\title{
Local Structure of Supported Keggin and Wells-Dawson Heteropolyacids and its Influence on the Catalytic Activity
}

\author{
Elisa I. García-López ${ }^{1}$, Giuseppe Marci ${ }^{2,}$, Igor Krivstov $^{3,4}$, \\ Jorge Casado Espina ${ }^{5}$, Leonarda F. Liotta ${ }^{6}$, Aida Serrano ${ }^{7, *}$
}

${ }^{1}$ Department of Biological, Chemical and Pharmaceutical Sciences and Technologies

(STEBICEF), Università di Palermo, Viale delle Scienze, 90128 Palermo, Italy.

2 "Schiavello-Grillone" Photocatalysis Group. Dipartimento di Ingegneria (DI), Università di Palermo, Viale delle Scienze, 90128 Palermo, Italy.

${ }^{3}$ Department of Organic and Inorganic Chemistry, University of Oviedo, 33006 Oviedo, Spain.

${ }^{4}$ Department of Environmental and Chemical Technology, South Ural State University, Chelyabinsk, Russia.

${ }^{5}$ Scientific Technical Services, University of Oviedo, 33006, Oviedo, Spain.

${ }^{6}$ Istituto per lo Studio dei Materiali Nanostrutturati (ISMN)-CNR, via Ugo La Malfa, 153, 90146 Palermo, Italy.

${ }^{7}$ Spanish CRG BM25 SpLine Beamline at the ESRF, 71 Avenue de Martyrs, F-38043 Grenoble, France.

*E-mails: giuseppe.marci@unipa.it, aida.serrano@icv.csic.es.

\section{Keywords}

heteropolyacid, polyoxometalate, Keggin, Wells-Dawson, structure-activity effect, catalysis, photocatalysis, XAS, XANES, EXAFS

\begin{abstract}
Keggin $\left[\mathrm{PW}_{12} \mathrm{O}_{40}\right]^{3-}$ and Wells-Dawson $\left[\mathrm{P}_{2} \mathrm{~W}_{18} \mathrm{O}_{62}\right]^{6-}$ heteropolyanions are nanosized transition metal-oxygen clusters belonging to the heteropolyacids (HPAs) family. They are widely used as catalysts, due to their strong Brönsted acidity, and their dispersion on solid supports favours the accessibility to their acid sites generally increasing the catalytic activity. A series of binary materials composed of Keggin or Wells-Dawson HPAs and $\mathrm{SiO}_{2}, \mathrm{TiO}_{2}$ and $\mathrm{ZrO}_{2}$ has been prepared by impregnation or solvothermal methods. Remarkable differences have been found in the catalytic activities among the unsupported and supported HPAs. These differences have been correlated in the past to the structural changes of the HPAs due to the cluster-support interaction, which is different depending on preparation methodologies of the binary material. In the present work, the modes of interaction between the two types of HPA, Keggin and Wells-Dawson, and various supports have been studied by X-ray absorption spectroscopy. The obtained data have been compared with the characterization of the same materials reported before by using different bulk and surface physicochemical techniques. The characterization results were then used to correlate the interaction modes between the HPAs and the supports with the catalytic performances reported for 2-propanol dehydration to propene and for propene hydration to 2-propanol. The results reveal that the deposition of HPA by impregnation or solvothermal treatment may cause distortions in the $\mathrm{H}_{3} \mathrm{PW}_{12} \mathrm{O}_{40}$ cluster structure depending on stronger $\left(\mathrm{TiO}_{2}\right.$ and $\left.\mathrm{ZrO}_{2}\right)$ or weaker $\left(\mathrm{SiO}_{2}\right)$ basic sites presence in the support, respectively. Moreover, the type of preparation method affects the structure and acidic properties of the supported HPAs. In particular, during the preparation of $\mathrm{TiO}_{2}$ and $\mathrm{ZrO}_{2}$ with $\mathrm{HPA}$ by in-situ solvothermal method, the reaction of the HPA with the products of metal alkoxides hydrolysis occurs with consequent destruction of the Keggin structure. Therefore, the catalytic activity of such materials is poor.

These modifications, in addition to the bulk and surface features of the supported HPAs, affected the catalytic 2-propanol dehydration to a significant extent. On the contrary, the propylene hydration was less influenced, probably, due to the propene non-polar nature.
\end{abstract}




\section{Introduction}

Metal oxides can be subdivided into classical solid oxides and nanosized transition metal oxygen clusters, also called polyoxometalates (POMs) that offer a fascinating range of structures and properties [1]. The most explored POM materials are the heteropolyacids (HPAs) which are strong inorganic acids possessing defined molecular structures. In order to classify the HPAs, one can consider the symmetrical 'parent' polyanion, among them the Keggin or Wells-Dawson structures. The use of HPAs in catalysis has attracted great interest because of their strong Brönsted acidity and redox abilities, so they are extensively used as bifunctional catalysts $[2,3]$. These materials are also economically and environmentally interesting because the majority of POMs are inexpensive and not toxic [4]. In addition, HPAs show photocatalytic activities both in homogeneous [5] and heterogeneous systems [6].

Wells-Dawson and Keggin heteropolytungstates are formed by polymeric $\mathrm{WO}_{6}$ units. The Keggin structure, in the polyanion $\left[\mathrm{PW}_{12} \mathrm{O}_{40}\right]^{3-}$, is composed of a globe-like cluster of corner and edge sharing $\mathrm{WO}_{6}$ units that enclose a central tetrahedron $\mathrm{PO}_{4}$. The tungsten $\mathrm{WO}_{6}$ units possess one short $\mathrm{W}=\mathrm{O}$ terminal bond, four $\mathrm{W}-\mathrm{O}-$ $\mathrm{W}$ bonds, and one long W-O-P bond to the central $\mathrm{PO}_{4}$ tetrahedron. The four peripheral $\left[\mathrm{W}_{3} \mathrm{O}_{13}\right]$ blocks complete twelve octahedra in total, whose centers are occupied by tungsten atoms, which are the so-called "addenda" atoms. This cluster has a diameter of ca. $1 \mathrm{~nm}[7,8]$ and, in the acidic form $\mathrm{H}_{3} \mathrm{PW}_{12} \mathrm{O}_{40}$ will be labelled in the following as $\mathrm{PW}_{12}$. The lack of one (monovacant) or more addenda atoms results in the formation of the 'lacunary' HPA, in contrast with the 'plenary' one. The phosphotungstic Wells-Dawson heteropolytungstate possesses the formula $\left[\mathrm{P}_{2} \mathrm{~W}_{18} \mathrm{O}_{62}\right]^{6-}$, and it may be considered being derived from two Keggin units [8,9]. In the following $\mathrm{H}_{6} \mathrm{P}_{2} \mathrm{~W}_{18} \mathrm{O}_{62}$ will be labelled as $\mathrm{P}_{2} \mathrm{~W}_{18}$. Figure 1 shows a geometrical representation of both Keggin (a) and Wells-Dawson (b) clusters. The orange central atom represents $\mathrm{P}$, whereas the blue octahedral positions of $\mathrm{W}$ are surrounded by oxygens, as red dots.

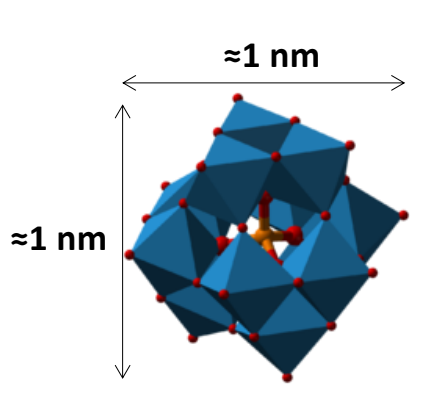

(a)

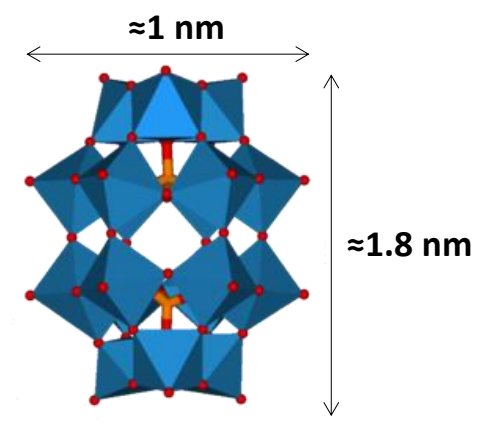

(b)

FIGURE 1. Polyhedral representations of the structures of (a) plenary Keggin-type $\left[\mathrm{PW}_{12} \mathrm{O}_{40}\right]^{3-}$ and (b) WellsDawson $\left[\mathrm{P}_{2} \mathrm{~W}_{18} \mathrm{O}_{62}\right]^{6-}$ heteropolyanions.

The acidity of both Keggin and Wells-Dawson HPAs is higher than that of mineral acids possessing pure Brönsted acidity. Their protons play a major role in catalytic active sites. Misono et al. determined the presence of hierarchical structures in HPAs i.e., primary, secondary and tertiary structures $[3,7]$ that result of paramount importance to understand their role as catalysts. The primary structure corresponds to those in Figure 1, i.e. the heteropolyanion itself; the secondary structure is assigned to a three-dimensional arrangement including counter cations, in our case $\mathrm{H}^{+}$and water molecules [3,7-10]. In addition, the arrangement of the particles, that is dependent on their morphology and size, generates the tertiary structure that is responsible for the surface area of HPAs and for the accessibility of substrates to the HPAs acid sites. The active sites in the solid bulk, i.e. the protons, represented by $\mathrm{H}_{5} \mathrm{O}_{2}{ }^{+}$species on the secondary structure, taking part in the catalytic reaction are the active Brönsted acid sites on the HPAs secondary structure. Polar reactants can be absorbed into and therein react in the pseudo-liquid phase reaction. Hence, according to Misono et al., the catalytic behaviour of HPAs is strongly influenced by the modifications that may occur in the secondary structure $[3,7,10]$ which would be altered by the number of water molecules involved. In this context, the catalytic behaviour of these materials is strongly influenced by the structural modifications that may occur in their primary, secondary and 
tertiary structures and it depends on their hydration state which determines the number and strength of surface acid sites along with the accessibility of the substrates to these acid sites [11,12]. The pseudo-liquid behaviour observed in catalytic reactions with HPAs is attributed to the flexibility of the HPA lattice, which allows that reagent molecules can be absorbed and react on the solid bulk. These properties provide to the HPA catalysts exclusive selectivity and high activity. However, it is important to highlight that the extent of the pseudo-liquid behaviour observed in catalytic reactions depends on the pre-catalytic treatment of HPAs [13] and, anyway, it concerns only polar reagents. Among the HPAs, those having Keggin-type structure are currently used in industrial catalytic processes [14] while the Wells-Dawson HPAs have been used for the important selective catalytic oxidative dehydrogenation of isobutane to 2-methyl-propene (isobutylene) [15] and for methyl tertbutyl ether (MTBE) production [16].

HPAs clusters have also been used as photocatalysts because they absorb light by the ground electronic state producing a charge transfer-excited state (HPA*) which can easily become HPA ${ }^{\mathrm{n}-}$, the so-called "heteropolyblue" species, by means of one (or more) electron transfer from another molecule. Heteropolyblues $\left(\mathrm{HPA}^{\mathrm{n}}\right)$ species are relatively stable and are readily re-oxidized [5]. The enhanced degradation of organic compounds in the $\mathrm{UV} / \mathrm{TiO}_{2}$ process in the presence of supported Keggin-type HPAs has been reported $[6,17,18]$.

Dispersing HPAs onto solid supports with high specific surface area is generally considered beneficial to increase their very low (ca. $5 \mathrm{~m}^{2} \mathrm{~g}^{-1}$ ) area which could hamper its use as heterogeneous catalysts. However, contrasting results are reported, depending upon the support and its degree of interaction with the HPA. Gaigneaux et al. have observed that the use of $\mathrm{TiO}_{2}$ as support, in comparison to the use of boron nitride with a more hydrophobic surface, could induce a better dispersion by virtue of its hydroxylated surface, but at the same time $\mathrm{TiO}_{2}$ could give rise to a decrease of the acidic strength of the HPA [19]. As far as the catalytic photo-assisted activity of the supported HPAs is concerned, it has been demonstrated that the use of semiconductor oxides as supports plays a beneficial role in the cluster photocatalytic activity due to the ability of the activated HPA* species to be reduced by the photogenerated electrons of the conduction band of the UVactivated semiconductor $[5,20]$.

In order to study the local structural effects generated by the supports on the HPAs clusters, X-ray absorption spectroscopy (XAS) can be very useful. XAS is one of the most employed techniques in the heterogeneous catalysis and can be stated as an informative spectroscopy to study W species on several supports [21-23]. A combination of X-ray absorption near-edge structure (XANES) and extended X-ray absorption fine structure (EXAFS) measurements can be employed to analyse the structural modification induced by the interaction between the HPAs and different supports as well as the diverse preparation methodologies, allowing us to estimate the oxidation state of the $\mathrm{W}$ absorbing atom and its local environment.

The present research aimed to study the local structures of the HPAs while supported on different oxide surfaces. Both commercial and home prepared supports have been impregnated with Keggin and WellsDawson HPAs. Additionally, an alternative preparation of the binary materials by solvothermal procedure has also been explored. Remarkable differences have been observed in the catalytic activity between the different HPAs/support binary materials, which were attributed to modifications in the HPA structure due to the interaction between the HPA and the support. The metal-oxygen cluster deformation could modify the composites acidity influencing the catalytic activity. The understanding of HPA rearrangements in the binary materials would help to elaborate and improve the existing preparation procedures for these catalysts.

\section{Experimental}

\section{1. (Photo)catalysts preparation}

Three sets of materials have been prepared by using the two HPAs, namely, the Keggin, $\mathrm{H}_{3} \mathrm{PW}_{12} \mathrm{O}_{40}$, provided by Aldrich (reagent grade 99.7\%), labelled as $\mathrm{PW}_{12}$, and the Wells-Dawson, $\mathrm{H}_{6} \mathrm{P}_{2} \mathrm{~W}_{18} \mathrm{O}_{60}$, labelled as $\mathrm{P}_{2} \mathrm{~W}_{18}$, which was prepared in our laboratory by following the procedure described elsewhere [24. In the first set of HPA supported samples, both Keggin and Wells-Dawson have been supported by wet 
impregnation on commercial $\mathrm{SiO}_{2}$ (fumed, Aldrich) or $\mathrm{TiO}_{2}$ (Evonik P25). The dispersion of the HPA onto the oxide surface was carried out by adding the $\mathrm{SiO}_{2}$ or $\mathrm{TiO}_{2}$ solid powder to an appropriate amount of the HPA solubilised in water. The resulting suspension was stirred for $1 \mathrm{~h}$, dried and annealed at $50{ }^{\circ} \mathrm{C}$ overnight. The resulting powders were labelled as $\mathrm{PW}_{12} / \mathrm{SiO}_{2}$ and $\mathrm{P}_{2} \mathrm{~W}_{18} / \mathrm{SiO}_{2}$ or $\mathrm{PW}_{12} / \mathrm{TiO}_{2}$ and $\mathrm{P}_{2} \mathrm{~W}_{18} / \mathrm{TiO}_{2}$ as described before in ref. [24]. The aqueous HPA suspension contained an amount of $\mathrm{PW}_{12}$ or $\mathrm{P}_{2} \mathrm{~W}_{18}$ enough to theoretically form ca. one monolayer of the HPA onto the oxide surface. Consequently, the quantity of HPA used was different for $\mathrm{HPA} / \mathrm{SiO}_{2}$ with respect to that used for $\mathrm{HPA} / \mathrm{TiO}_{2}$ materials depending upon the oxide specific surface area (SSA). The theoretical coverage has been calculated by taking into account the diameter of the anionic HPA cluster, which was considered equal to ca. $1 \mathrm{~nm}$ for both Keggin and WellsDawson, therefore, by considering a roundish shape, its surface area resulted ca. $78.5 \AA^{2}$ in the case of Keggin HPA. According to Sambeth et al., the parameters of the primary Wells-Dawson HPA structure can be assumed as a rectangular prism sized $(21.5 \times 15.5 \times 12.1) \AA$ [25]; consequently, the area occupied by each cluster resulted ca. 94 and $167 \AA^{2}$ (we have considered an average value of $130 \AA^{2}$ ) by considering the upright and reclined species, respectively.

A second set of samples corresponds to those materials where the HPA, in this case only $\mathrm{PW}_{12}$, has been supported by impregnation onto home prepared oxides, i.e. $\mathrm{SiO}_{2}, \mathrm{TiO}_{2}, \mathrm{ZrO}_{2}$ (samples bearing the suffix A, meaning that the oxide has been prepared by a solvothermal method from an alkoxide). The detailed preparation of the $\mathrm{SiO}_{2} \mathrm{~A}$ and $\mathrm{TiO}_{2} \mathrm{~A}$ oxides has been explained in our previous research, where sol-gel methodology by using alkoxides, i.e. tetraethylortosilicate or titanium isopropoxide, with a successive solvothermal treatment was used [26]. $\mathrm{ZrO}_{2}$ has been analogously prepared starting from zirconium butoxide. $39 \mathrm{ml}$ of the alkoxide where hydrolysed in $50 \mathrm{ml}$ of water and the suspension transferred into a Teflon autoclave and treated solvothermally for $48 \mathrm{~h}$ at $200{ }^{\circ} \mathrm{C}$. The final solid was filtered, washed with water and dried to obtain the final oxide $\mathrm{ZrO}_{2} \mathrm{~A}$. The impregnation of certain amount of $\mathrm{SiO}_{2} \mathrm{~A}\left(195 \mathrm{~m}^{2} \mathrm{~g}^{-1}\right), \mathrm{TiO}_{2} \mathrm{~A}\left(161 \mathrm{~m}^{2} \mathrm{~g}^{-1}\right)$ and $\mathrm{ZrO}_{2} \mathrm{~A}\left(110 \mathrm{~m}^{2} \mathrm{~g}^{-1}\right)$ with an aqueous solution containing sufficient $\mathrm{PW}_{12}$ amount to theoretically form ca. one monolayer of HPA onto the support surface, was carried out [24,26].

A third set of samples, bearing the suffix exA, as reported in Table 1, has been prepared by adding the correspondent alkoxide to an aqueous solution containing $\mathrm{PW}_{12}$. The hydrolysis of the alkoxide was carried out in the presence of the HPA. The resulting suspension after ca. $0.5 \mathrm{~h}$ of stirring was solvothermally treated for $48 \mathrm{~h}$ at $200{ }^{\circ} \mathrm{C}$. The amount of $\mathrm{PW}_{12}$ was that enough to theoretically form ca. one monolayer of the HPA onto the oxide surface possessing the surface area of that prepared in the same conditions in the absence of the HPA. The final powder was filtered, washed and dried. The preparation of these materials has been thoroughly described before [26]. Table 1 summarizes the prepared powders.

TABLE 1. Pristine and supported HPA samples: preparation method, specific surface areas (SSA) and the theoretical mass percentage of HPA.

\begin{tabular}{|c|c|c|c|}
\hline \multirow{4}{*}{ Pristine materials } & Sample & $\mathrm{SSA}\left[\mathrm{m}^{2} \cdot \mathrm{g}^{-1}\right]$ & Mass percentage of HPA [\%] \\
\cline { 2 - 4 } & $\mathrm{SiO}_{2}$ & 319 & - \\
\cline { 2 - 4 } & $\mathrm{TiO}_{2}$ & 52 & - \\
\cline { 2 - 4 } & $\mathrm{PW}_{12}$ & 15 & - \\
\cline { 2 - 4 } & $\mathrm{P}_{2} \mathrm{~W}_{18}$ & 5 & 70 \\
\hline \multirow{4}{*}{$\begin{array}{c}\text { (HPA impregnation on } \\
\text { commercial oxides) }\end{array}$} & $\mathrm{PW}_{12} / \mathrm{SiO}_{2}$ & 53 & 26 \\
\cline { 2 - 4 } & $\mathrm{PW}_{12} / \mathrm{TiO}_{2}$ & 50 & 26 \\
\cline { 2 - 4 } & $\mathrm{P}_{2} \mathrm{~W}_{18} / \mathrm{SiO}_{2}$ & 38 & 58 \\
\cline { 2 - 4 } & $\mathrm{P}_{2} \mathrm{~W}_{18} / \mathrm{TiO}_{2}$ & 46 & 40 \\
\hline \multirow{3}{*}{$\begin{array}{c}\text { (HPA impregnation on } \\
\text { home prepared materials) }\end{array}$} & $\mathrm{PW}_{12} / \mathrm{SiO}_{2} \mathrm{~A}$ & 32 & 36 \\
\cline { 2 - 4 } & $\mathrm{PW}_{12} / \mathrm{TiO}_{2} \mathrm{~A}$ & 43 & $\mathrm{PW}$ \\
\cline { 2 - 4 } & $\mathrm{PW}_{12} / \mathrm{ZrO}_{2} \mathrm{~A}$ & 95 & \\
\hline
\end{tabular}




\begin{tabular}{|c|l|l|l|}
\hline \multirow{3}{*}{$\begin{array}{c}3_{\text {sd }}^{\text {rd }} \text { set } \\
\text { of the composmal preparation }\end{array}$} & $\mathrm{PW}_{12} / \mathrm{SiO}_{2}$ exA & 219 & 58 \\
\cline { 2 - 4 } & $\mathrm{PW}_{12} / \mathrm{TiO}_{2}$ exA & 161 & 40 \\
\cline { 2 - 4 } & $\mathrm{PW}_{12} / \mathrm{ZrO}_{2}$ exA & 145 & 36 \\
\hline
\end{tabular}

\subsection{Surface, bulk and structural characterization of the (photo)catalysts}

\subsubsection{XRD, SEM/EDX, SSA measurements, Raman, FTIR and XPS characterization}

Bulk and surface characterizations were carried out in order to define the physico-chemical properties of the powders. Crystalline structure of the samples was determined at room temperature by powder X-ray diffraction analysis (PXRD) carried out by using a Palytical Empyrean, equipped with CuKa radiation and PixCel1D (tm) detector. Scanning electron microscopy (SEM) was performed using a FEI Quanta 200 ESEM microscope, operating at $20 \mathrm{kV}$ on specimens upon which a thin layer of gold had been evaporated. An electron microprobe used in an energy dispersive mode (EDX) was employed to obtain information on the actual metal (tungsten) content present in the samples and consequently the actual HPA loading. Moreover, EDX analysis allowed to evaluate the overall dispersion of the HPA on the support. Specific surface area and porosity were determined in accordance with the standard Brunauer-Emmet-Teller (BET) method from the nitrogen adsorptiondesorption isotherm using a Micromeritics ASAP 2020.

Vibrational spectroscopies, FTIR and Raman, were used to verify the structural integrity of the HPA cluster after the formation of the binary material. FTIR spectra of the samples in $\mathrm{KBr}$ (Aldrich) pellets were obtained by using a FTIR- 8400 Shimadzu spectrometer with $4 \mathrm{~cm}^{-1}$ resolution and 256 scans. Raman spectra were recorded by a Renishaw in-via instrument equipped with an integrated microscope and with a charge-coupled device (CCD) camera. A He/Ne laser operating at $632.8 \mathrm{~nm}$ was used as the exciting source. The surface composition and binding energies of the elements constituting the prepared catalysts were measured by X-ray Photoelectron Spectroscopy (XPS), using a SPECS system equipped with a Hemispherical Phoibos analyzer operating in a constant pass energy, using $\mathrm{Mg} \mathrm{K \alpha}$ radiation $(\mathrm{h} \cdot \mathrm{v}=1253.6 \mathrm{eV})$ at a voltage of $13 \mathrm{kV}, 225 \mathrm{~W}$ power and the emission intensity of $17.5 \mathrm{~mA}$. The deconvolution of the $\mathrm{W} 4 \mathrm{f}$ spectra for the pristine and supported HPA samples was carried out considering the $4 \mathrm{f}$ orbital split of about 2.1-2.2 eV and the peak ratio of the $4 \mathrm{f}_{7 / 2}$ to $4 \mathrm{f}_{5 / 2}$ contributions of $4: 3$ as constraints.

\subsubsection{XAS measurements: XANES and EXAFS}

XAS measurements at the $\mathrm{W} \mathrm{L}_{3}$ and $\mathrm{L}_{1}$-edge were performed at the CRG-BM25A SpLine beamline in The European Synchrotron (ESRF), Grenoble (France). The beamline monochromator is a pseudo channel-cut with two $\mathrm{Si}(111)$ crystals refrigerated at $200 \mathrm{~K}$ by a homemade ethanol cooling system. The energy calibration for all scans was carried out with a $\mathrm{Zn}$ foil. XAS data were collected in transmission mode at room temperature and a total of two scans were measured to average. The gas ionization chamber used to collect the incident beam intensity was filled with $7 \% \mathrm{Ar}$ and $93 \% \mathrm{~N}_{2}$, whereas the chamber employed to measure the absorbed signal was filled of $95 \%$ Ar and $5 \% \mathrm{Kr}$. XAS studies were focused on both XANES and EXAFS signals in order to reveal information about the local symmetry, coordination number, valence and local structure [27]. The X-ray absorption data were analysed with a standard procedure using ATHENA and ARTEMIS software [28].

\subsubsection{Measurements of acidic sites amounts and their strength}

The acidity of the (photo)catalysts was determined by temperature-programmed desorption of ammonia $\left(\mathrm{NH}_{3}-\right.$ TPD) experiments that were carried out with a Micromeritics Autochem 2950 apparatus equipped with a thermal conductivity detector (TCD), a quadrupole mass (QM) spectrometer (Thermostar, Balzers) and an ultraviolet gas analyzer (ABB, Limas 11). Samples were pre-treated in $\mathrm{He}$ flow at $100{ }^{\circ} \mathrm{C}$ for $30 \mathrm{~min}$ and after cooling down at room temperature, ammonia adsorption was performed by admitting a flow of $5 \% \mathrm{NH}_{3}$ 
containing He stream $\left(30 \mathrm{ml} \mathrm{min}^{-1}\right)$ for $1 \mathrm{~h}$. In order to remove all the physically adsorbed ammonia, samples were purged by flowing $100 \mathrm{ml} \mathrm{min}{ }^{-1}$ of $\mathrm{He}$ at $100{ }^{\circ} \mathrm{C}$ for $1 \mathrm{~h}$. Then, after cooling down at room temperature, ammonia desorption started by flowing $\mathrm{He}\left(30 \mathrm{ml} \mathrm{min}{ }^{-1}\right.$ ) and heating up to $600{ }^{\circ} \mathrm{C}$ (rate of $10{ }^{\circ} \mathrm{C} \mathrm{min}^{-1}$ ), holding time at $600{ }^{\circ} \mathrm{C}$ for $30 \mathrm{~min}$. Ammonia concentration profiles were recorded with the ultraviolet gas analyzer. TCD and QM data were used to qualitatively confirm the trends.

\subsubsection{Catalytic activity}

The catalytic activity set-up has been used before for 2-propanol dehydration [24,26] or propylene hydration [29-31] in the presence of the $\mathrm{SiO}_{2}$ and $\mathrm{TiO}_{2}$ supported HPA. In brief, it consisted of a horizontally positioned cylindrical continuous Pyrex photoreactor (diameter: $10 \mathrm{~mm}$, length: $100 \mathrm{~mm}$ ), where $0.5 \mathrm{~g}$ of solid powder were placed as a thin layer. A porous glass septum allowed to homogeneously distribute the gaseous inlet mixture. For the experiments of 2-propanol dehydration, a flow consisting of nitrogen containing 2-propanol added by means of an infusion pump, with a concentration of $0.5 \mathrm{mM}$ with a gaseous stream of $100 \mathrm{ml} \cdot \mathrm{min}^{-1}$. For the hydration catalytic experiments, the gas feeding the photoreactor consisted of propene and water with molar concentrations of ca. $40 \mathrm{mM}$ and $2 \mathrm{mM}$, respectively. The mass flow controller allowed to feed gaseous propene, whereas water was mixed with the propene stream by means of the infusion pump. The flow rate of the gaseous stream for the runs was $20 \mathrm{ml} \cdot \mathrm{min}^{-1}$. A pre-treatment of the catalysts was carried out under $\mathrm{N}_{2}$ at $100{ }^{\circ} \mathrm{C}$ for $0.5 \mathrm{~h}$. All the catalytic experiments have been carried out at atmospheric pressure at a temperature of ca. $85^{\circ} \mathrm{C}$. The reacting fluid was analysed by a GC-2010 Shimadzu gas chromatograph equipped with a Phenomenex Zebron Wax-plus column and a FID.

\section{Results and discussion}

\subsection{XRD, SEM/EDX, SSA, Raman, FTIR and XPS characterization}

A physicochemical characterization of $\mathrm{PW}_{12}$ and $\mathrm{P}_{2} \mathrm{~W}_{18}$ on $\mathrm{SiO}_{2}$ and $\mathrm{TiO}_{2}$ composites studied in the present research has been reported in previous works [24,26]. Both pristine $\mathrm{PW}_{12}$ and $\mathrm{P}_{2} \mathrm{~W}_{18} \mathrm{XRD}$ patterns showed several diffraction peaks evidencing the crystalline nature of the secondary and tertiary structure of the HPA [24].

All the binary materials studied here, prepared by using commercial and home prepared supports, presented XRD patterns where the main peaks attributed to the $\mathrm{PW}_{12}$ were present, however showing very weak intensities due to both the low amount of HPA and also a good dispersion on the support. For the in-situ preparation of the supports along with the HPA under hydrothermal conditions (exA composites), the peaks attributable to the $\mathrm{PW}_{12}$ were absent. The predominant maxima on the composites XRD patterns correspond to those related to the support for all of the binary materials. The characteristic $\mathrm{P}_{2} \mathrm{~W}_{18}$ reflections cannot be observed for $\mathrm{P}_{2} \mathrm{~W}_{18} / \mathrm{TiO}_{2}$ nor for $\mathrm{P}_{2} \mathrm{~W}_{18} / \mathrm{SiO}_{2}$, due to their good dispersion on the surface of the support, as confirmed by EDX [24]. XRD patterns were reported before for the binary powders on $\mathrm{SiO}_{2}$ and $\mathrm{TiO}_{2}$ [24,26,29-31]. SEM/EDX characterization showed that the morphology of the supported materials was nearly the same to that of the bare support. EDX analysis revealed that "W" amounts resulted homogeneously distributed on the particles surface. Unfortunately, due to the partial overlapping of $\mathrm{Si}$ and $\mathrm{W}$ signals in $\mathrm{SiO}_{2}$ based catalyst it was not possible to properly analyse the percentage of $\mathrm{Si}$ and $\mathrm{W}$ for these samples. Anyhow, the measured HPA-support ratios for the other samples were very close to the nominal ones (values reported in Table 1) showing small oscillations between the probes taken from different areas of the samples, indicating a good dispersion of HPA $[24,26]$. The SSAs of the commercial supports are reported in Table 1. The SSA of home prepared solvothermally obtained $\mathrm{SiO}_{2} \mathrm{~A}, \mathrm{TiO}_{2} \mathrm{~A}$ and $\mathrm{ZrO}_{2} \mathrm{~A}$ were $195,161,110 \mathrm{~m}^{2} \mathrm{~g}^{-1}$, respectively. In general, the SSA of the binary materials decreased with respect to the bare supports, as shown in Table 1. The blockage of the pores of the oxides, due to the presence of the HPA clusters, could explain this result. On the contrary, it is remarkable that the SSA of the composite materials prepared solvothermally $\left(\mathrm{PW}_{12} / \mathrm{SiO}_{2}\right.$ exA; $\mathrm{PW}_{12} / \mathrm{TiO}_{2}$ exA; $\mathrm{PW}_{12} / \mathrm{ZrO}_{2}$ exA) did not decrease compared to the bare solvothermally prepared bare 
oxides $\left(\mathrm{SiO}_{2} \mathrm{~A} ; \mathrm{TiO}_{2} \mathrm{~A} ; \mathrm{ZrO}_{2} \mathrm{~A}\right)$, indicating that the $\mathrm{PW}_{12}$ has been incorporated into the porous structure of the binary system without reducing the porosity of the oxide, as reported in previous research [24,26].

As we have previously published, both Raman and FTIR spectra confirmed the retention of both Keggin and Wells-Dawson structures after the impregnation of the $\mathrm{HPA}$ onto commercial $\mathrm{SiO}_{2}$ and $\mathrm{TiO}_{2}$ oxide surfaces [24] and the same occurred on home prepared $\mathrm{SiO}_{2}$ and $\mathrm{TiO}_{2}$ [26]. Indeed, the spectra of both pristine $\mathrm{PW}_{12}$ and $\mathrm{P}_{2} \mathrm{~W}_{18}$ showed their characteristic strong vibration bands, and the dispersion of the $\mathrm{HPAs}$ on $\mathrm{SiO}_{2}$ and $\mathrm{TiO}_{2}$ did not shift their vibrational modes. For $\mathrm{PW}_{12}$, the four characteristic bands attributed to the cluster were maintained in $\mathrm{PW}_{12} / \mathrm{SiO}_{2} \mathrm{~A}, \mathrm{PW}_{12} / \mathrm{TiO}_{2} \mathrm{~A}$ and $\mathrm{PW}_{12} / \mathrm{ZrO}_{2} \mathrm{~A}$ and $\mathrm{PW}_{12} / \mathrm{SiO}_{2}$ exA with no significant shift, as previously reported by some of us [26]. On the contrary, the solvothermal preparation of $\mathrm{PW}_{12} / \mathrm{TiO}_{2}$ exA and $\mathrm{PW}_{12} / \mathrm{ZrO}_{2}$ exA composites gave rise to materials in which the heteropolyacid skeletal vibrations are not clearly evident [26] and only the $v_{\mathrm{as}}\left(\mathrm{W}=\mathrm{O}_{\mathrm{d}}\right)$ was observed, although, red shifted of ca. $10 \mathrm{~cm}^{-1}$ with respect to the pristine $\mathrm{PW}_{12}$, indicating a stronger interaction between the heteropolyacid and the support as previously observed by Orel et al. [32] with analogous samples.

The structure of the Keggin cluster was also preserved in both the binary $\mathrm{PW}_{12} / \mathrm{SiO}_{2}$ exA and in $\mathrm{PW}_{12} / \mathrm{ZrO}_{2}$ exA samples, with slight widening of the vibration bands that can be attributed to electrostatic interaction with the support. On the contrary, as previously reported [26], in $\mathrm{PW}_{12} / \mathrm{TiO}_{2}$ exA, both FTIR and Raman spectra evidenced that the Keggin structure was strongly compromised not only because the characteristic $\mathrm{PW}_{12}$ vibration modes were absent, but because a new band at $961 \mathrm{~cm}^{-1}$ attributed to a vibration mode of a strong deformed Keggin cluster structure appeared.

The XPS spectrum of the $\mathrm{W} 4 \mathrm{f}$ region of unsupported Keggin HPA $\left(\mathrm{PW}_{12}\right)$ revealed the presence of tungsten species in oxidation state VI and V. The W(VI) manifested itself by a doublet with a characteristic peak

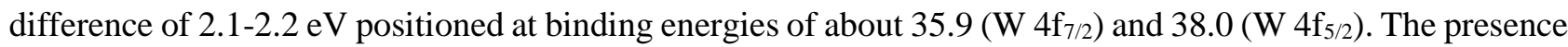

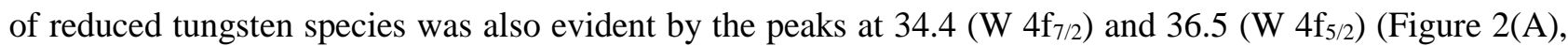
Table 2). Although, considering the colour change occurring during the measurements, one can suppose that the partial reduction of W was most likely to take place at high vacuum of the XPS system. Similar observations were made earlier by Haber et al. [33]. The $\mathrm{O} 1 \mathrm{~s}$ spectrum also indicated on the presence of reduced tungsten in the pristine $\mathrm{PW}_{12}$, the peak attributed to the oxygen of W-O-W bonds was significantly displaced to 530.2 $\mathrm{eV}$ (Figure 2(B)) compared to that reported in literature [34]. Another maximum appearing at $532.4 \mathrm{eV}$ was likely to be assigned to the oxygen of W-O-P and W-O-H groups, while the one at the highest binding energies showed the presence of coordination water molecules (Figure 2(B)).
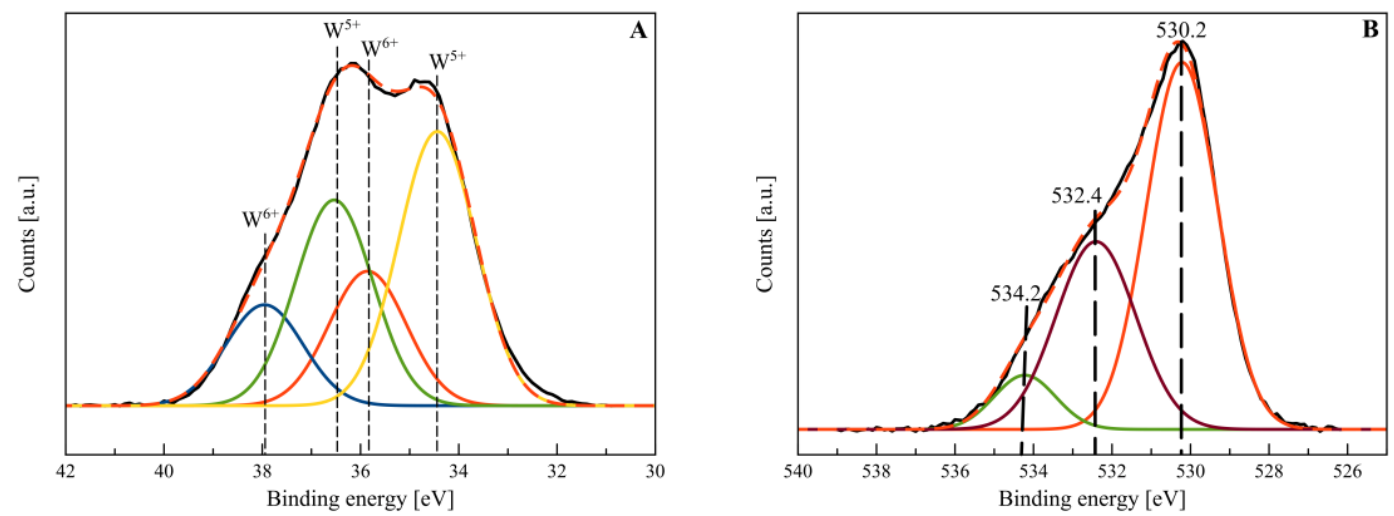

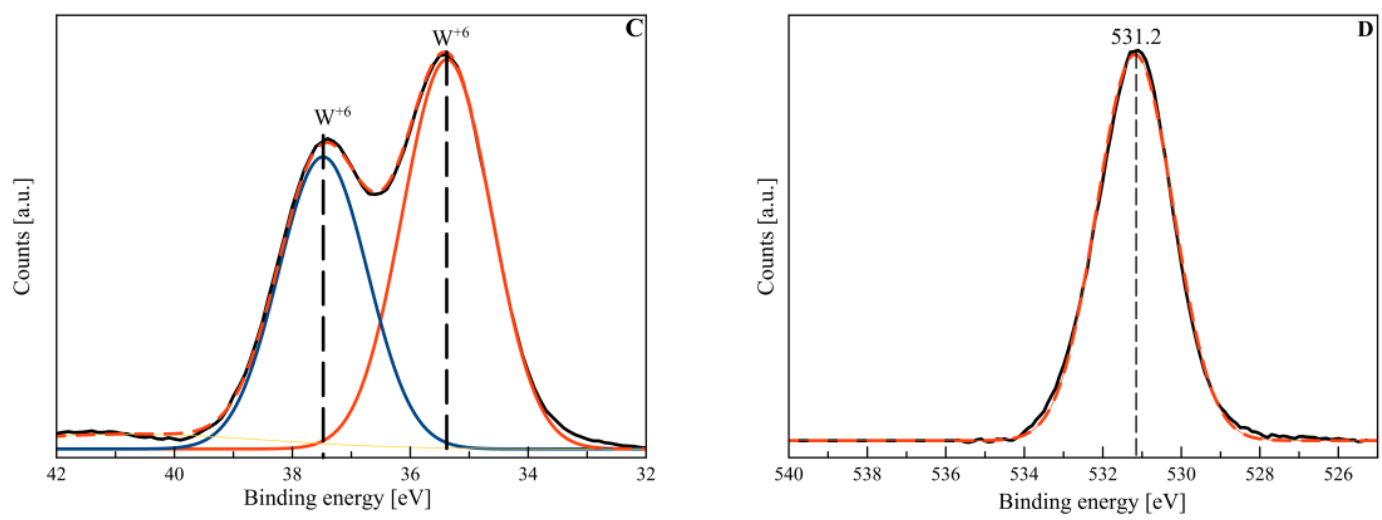

FIGURE 2. XPS spectra deconvolution of the $\mathrm{W} 4 \mathrm{f}$ region and $\mathrm{O} 1 \mathrm{~s}$ of the $\mathrm{PW}_{12}(\mathrm{~A}, \mathrm{~B})$ and $\mathrm{P}_{2} \mathrm{~W}_{18}(\mathrm{C}, \mathrm{D})$ pristine HPAs, respectively.

Unlike Keggin $\mathrm{PW}_{12}$, the XPS spectrum of the $\mathrm{W} 4 \mathrm{f}$ region of Wells-Dawson $\mathrm{P}_{2} \mathrm{~W}_{18}$ did not show the presence of the reduced $\mathrm{W}$ species and its deconvolution revealed only two peaks corresponding to the $4 \mathrm{f}_{7 / 2}$ and $4 \mathrm{f}_{5 / 2}$ contributions with the FWHM values of $1.8 \mathrm{eV}$ (Figure 2(C)). Consequently, the $\mathrm{O} 1 \mathrm{~s}$ spectrum was also satisfactory fitted with only one Gaussian function centred at $531.2 \mathrm{eV}$ (Figure 2(D)).

XPS surface elemental analysis presented in Table 2 reveals significantly higher surface concentration of HPA for $\mathrm{PW}_{12}$ and $\mathrm{P}_{2} \mathrm{~W}_{18}$ deposited on commercial $\mathrm{TiO}_{2}$ rather than on commercial $\mathrm{SiO}_{2}$. Dissolved $\mathrm{HPA}$ can easily penetrate inside the silica particles, due to its high SSA, amorphous nature and the presence of micro- and mesopores, hence surface sensitive XPS technique shows low W concentration. On the other hand, non-porous crystalline commercial $\mathrm{TiO}_{2}$ can accommodate $\mathrm{PW}_{12}$ and $\mathrm{P}_{2} \mathrm{~W}_{18}$ species only on its external surface, thus leading to a high surface-to-bulk ratio of the $\mathrm{W}$ content in this material (Table 2).
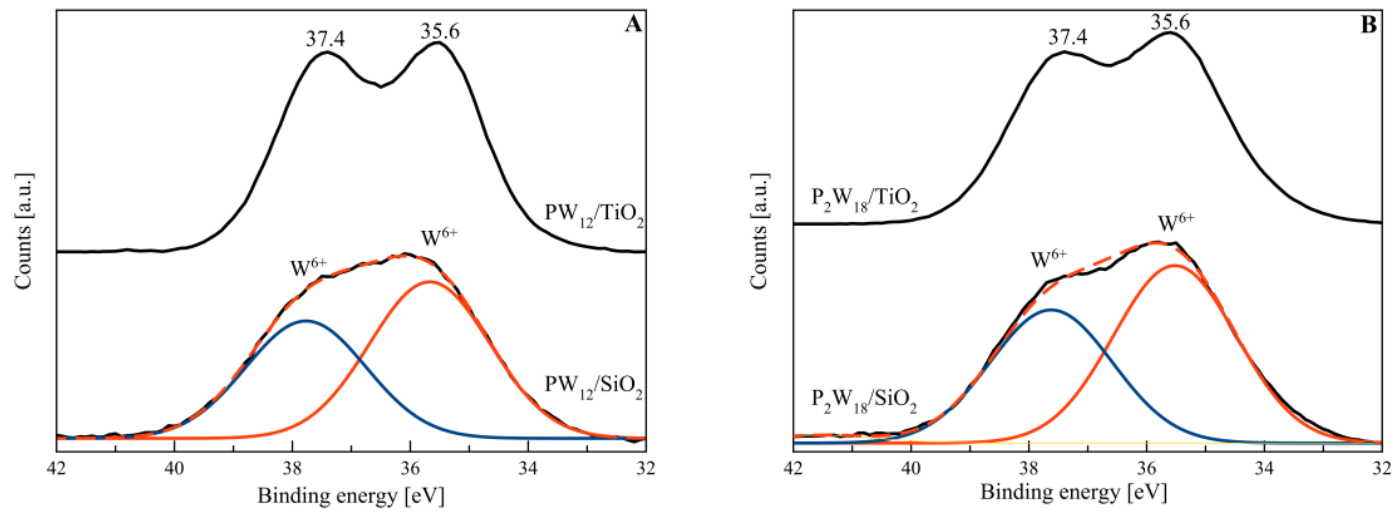

FIGURE 3. XPS spectra of the $\mathrm{W} 4 \mathrm{f}$ region and their deconvolution for the supported $\mathrm{PW}_{12}(\mathrm{~A})$ and $\mathrm{P}_{2} \mathrm{~W}_{18}(\mathrm{~B})$ samples on commercial $\mathrm{TiO}_{2}$ and $\mathrm{SiO}_{2}$.

Apparently, the deposition of HPA on the commercial $\mathrm{SiO}_{2}$ support stabilizes tungsten species from reduction inside the XPS apparatus, since the fit of $\mathrm{W}(\mathrm{V})$ into the spectrum has not led to satisfactory results. Nonetheless, the fitting of two peaks corresponding to the $\mathrm{W}(\mathrm{VI}) 4 \mathrm{f}_{7 / 2}$ and $4 \mathrm{f}_{5 / 2}$ contributions resulted in significantly higher FWHM values than that of the pristine HPA (Figure 3(A), Table 2). The increase in the FWHM parameter might be explained by the presence of various $\mathrm{PW}_{12}$ clusters deposited on the silica surface and inside the pores, which is in agreement with the drastically decreased SSA values of silica observed after the impregnation with $\mathrm{PW}_{12}$ (Table 1). Unfortunately, the fitting of the $\mathrm{W}$ 4f spectrum for the $\mathrm{TiO}_{2}-\mathrm{HPA}$ samples might give unreliable data, due to the overlapping of the signal with that of Ti 3p. However, one can assume that the peak maxima at 37.4 and $35.6 \mathrm{eV}$ lie in the range characteristic of W (VI) (Figure 3(A)). The XPS data obtained for the $\mathrm{P}_{2} \mathrm{~W}_{18}$ deposited on the surface of commercial $\mathrm{SiO}_{2}$ and $\mathrm{TiO}_{2}$ is almost similar to 
the case of Keggin HPA impregnated into these supports (Figure 3(B)). High FWHM values observed for the deconvoluted XPS W $4 \mathrm{f}$ profile of the $\mathrm{P}_{2} \mathrm{~W}_{18} / \mathrm{SiO}_{2}$ sample also suggests the presence of different HPA species immobilized inside the silica porous structure and on its surface (Figure 3(B), Table 2). The XPS W 4f spectrum of $\mathrm{P}_{2} \mathrm{~W}_{18} / \mathrm{TiO}_{2}$ is nearly identical to that of the $\mathrm{PW}_{12} / \mathrm{TiO}_{2}$ sample (Figure 3(B)).
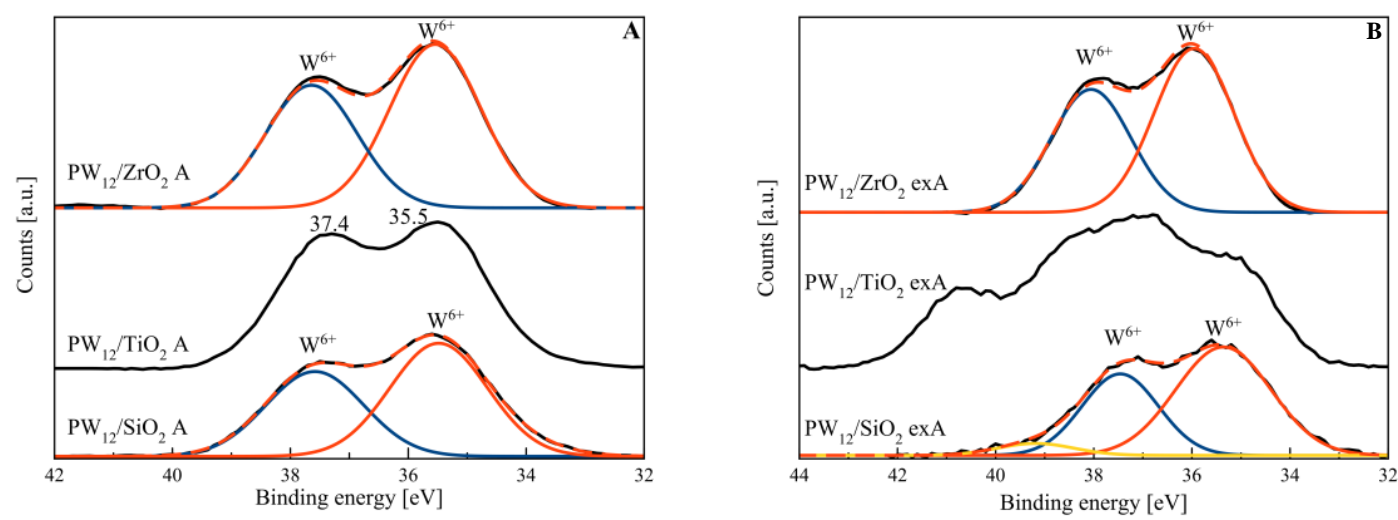

FIGURE 4. XPS spectra of the $\mathrm{W} 4 \mathrm{f}$ region and their deconvolution for the $\mathrm{PW}_{12}$ supported on home-prepared oxides $\left(\mathrm{SiO}_{2}, \mathrm{TiO}_{2}\right.$ and $\left.\mathrm{ZrO}_{2}\right)$ by the alkoxides $(\mathrm{A})$ and by in-situ solvothermal procedure (B).

The surface composition analysis for the $\mathrm{PW}_{12}$ supported on home-prepared oxides showed similar results to those obtained for the HPA deposited onto commercial oxides. The concentration of $\mathrm{W}$ is significantly higher in $\mathrm{PW}_{12} / \mathrm{TiO}_{2} \mathrm{~A}$ and $\mathrm{PW}_{12} / \mathrm{ZrO}_{2} \mathrm{~A}$ than in the $\mathrm{PW}_{12} / \mathrm{SiO}_{2} \mathrm{~A}$ samples owing to the developed porous structure of the silica support (Table 2).

Unlike in the case of $\mathrm{PW}_{12} / \mathrm{SiO}_{2}$, the deconvolution of the XPS W $4 \mathrm{f}$ spectrum of the $\mathrm{PW}_{12} / \mathrm{SiO}_{2} \mathrm{~A}$ sample

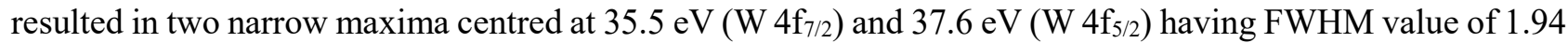
$\mathrm{eV}$ (Figure 4(A), Table 2). This possibly indicates a more homogeneous distribution of the HPA species in the home-prepared silica support than in the commercial one. The XPS W 4 f spectrum of the $\mathrm{PW}_{12} / \mathrm{TiO}_{2} \mathrm{~A}$ sample shows almost the same position of the two peaks as for the $\mathrm{PW}_{12} / \mathrm{TiO}_{2}$ material (Figure 4(A)). The interaction of HPA with zirconia differs to that with other studied oxides as the FWHM values obtained for the spectrum deconvolution are in the range of $1.84 \mathrm{eV}$ coinciding with the FWHM determined for the pristine $\mathrm{PW}_{12}$ (Figure 2(A), Table 2). This suggests that the deposited HPA species are predominantly found in one structural state. The in-situ preparation of the supports along with the $\mathrm{PW}_{12}$ under hydrothermal conditions (exA composites) was also analysed by XPS technique, leading to the lowest W/X (X indicating Si, Ti or Zr) ratios among the all impregnation approaches used in this study (Table 2, Figure 4(B)). This can be attributed to a higher degree of incorporation of $\mathrm{PW}_{12}$ into the interior of the oxide particles and accompanied by a decomposition of the $\mathrm{PW}_{12}$ and formation of $\mathrm{W}-\mathrm{O}-\mathrm{X}$ bonds, as confirmed by the study of these composites by vibrational spectroscopies, particularly for $\mathrm{PW}_{12} / \mathrm{TiO}_{2}$ exA [26].

TABLE 2. XPS surface elemental composition and the results of the $\mathrm{W} 4 \mathrm{f}$ spectra analysis.

\begin{tabular}{|c|c|c|c|c|}
\hline \multirow[t]{2}{*}{ Samples } & \multirow[t]{2}{*}{$\begin{array}{l}\text { XPS surface } \\
\text { composition }\end{array}$} & \multirow[t]{2}{*}{$\begin{array}{c}{ }^{\mathrm{a} W} / \mathrm{X} \text { surface } \\
\text { ratio }\end{array}$} & \multicolumn{2}{|c|}{$\begin{array}{c}\text { W 4f peak positions / FWHM } \\
{[\mathrm{eV}]}\end{array}$} \\
\hline & & & $\mathrm{W} 4 \mathrm{f}_{7 / 2}$ & $\mathrm{~W} 4 \mathrm{f}_{5 / 2}$ \\
\hline $\mathrm{PW}_{12}$ & $\mathrm{~W}_{16.5} \mathrm{O}_{77.1} \mathrm{P}_{6.4}$ & - & $\begin{array}{l}\left(\mathrm{W}^{6+}\right) 35.9 / 1.84 \\
\left(\mathrm{~W}^{5+}\right) 34.4 / 1.84\end{array}$ & $\begin{array}{l}\left(\mathrm{W}^{6+}\right) 38.0 / 1.84 \\
\left(\mathrm{~W}^{5+}\right) 36.5 / 1.84\end{array}$ \\
\hline $\mathrm{P}_{2} \mathrm{~W}_{18}$ & $\mathrm{~W}_{22.9} \mathrm{O}_{72.7} \mathrm{P}_{4.4}$ & - & $\left(\mathrm{W}^{6+}\right) 35.4 / 1.78$ & $\left(\mathrm{~W}^{6+}\right) 37.5 / 1.78$ \\
\hline $\mathrm{PW}_{12} / \mathrm{SiO}_{2}$ & $\mathrm{Si}_{35.8} \mathrm{O}_{63.0} \mathrm{~W}_{0.9} \mathrm{P}_{0.3}$ & 0.03 & $\left(\mathrm{~W}^{6+}\right) 35.7 / 2.40$ & $\left(\mathrm{~W}^{6+}\right) 37.8 / 2.40$ \\
\hline $\mathrm{PW}_{12} / \mathrm{TiO}_{2}$ & $\mathrm{Ti}_{19.3} \mathrm{O}_{71.9} \mathrm{~W}_{7.6} \mathrm{P}_{1.2}$ & 0.39 & - & - \\
\hline
\end{tabular}




\begin{tabular}{|c|c|c|c|c|}
\hline $\mathrm{P}_{2} \mathrm{~W}_{18} / \mathrm{SiO}_{2}$ & $\mathrm{Si}_{37.2} \mathrm{O}_{61.8} \mathrm{~W}_{1.7} \mathrm{P}_{0.4}$ & 0.05 & $\left(\mathrm{~W}^{6+}\right) 35.5 / 2.40$ & $\left(\mathrm{~W}^{6+}\right) 37.6 / 2.40$ \\
\hline $\mathrm{P}_{2} \mathrm{~W}_{18} / \mathrm{TiO}_{2}$ & $\mathrm{Ti}_{15.9} \mathrm{O}_{71.4} \mathrm{~W}_{11.0} \mathrm{P}_{1.6}$ & 0.69 & - & - \\
\hline $\mathrm{PW}_{12} / \mathrm{SiO}_{2} \mathrm{~A}$ & $\mathrm{Si}_{34.4} \mathrm{O}_{62.6} \mathrm{~W}_{2.4} \mathrm{P}_{0.6}$ & 0.07 & $\left(\mathrm{~W}^{6+}\right) 35.5 / 1.94$ & $\left(\mathrm{~W}^{6+}\right) 37.6 / 1.94$ \\
\hline $\mathrm{PW}_{12} / \mathrm{TiO}_{2} \mathrm{~A}$ & $\mathrm{Ti}_{19.3} \mathrm{O}_{72.7} \mathrm{~W}_{6.6} \mathrm{P}_{1.4}$ & 0.34 & - & - \\
\hline $\mathrm{PW}_{12} / \mathrm{ZrO}_{2} \mathrm{~A}$ & $\mathrm{Zr}_{17.5} \mathrm{O}_{73.6} \mathrm{~W}_{6.5} \mathrm{P}_{2.4}$ & 0.37 & $\left(\mathrm{~W}^{6+}\right) 35.5 / 1.82$ & $\left(\mathrm{~W}^{6+}\right) 37.6 / 1.82$ \\
\hline $\mathrm{PW}_{12} / \mathrm{SiO}_{2}$ exA & $\mathrm{Si}_{35.9} \mathrm{O}_{63.2} \mathrm{~W}_{0.7} \mathrm{P}_{0.2}$ & 0.02 & $\left(\mathrm{~W}^{6+}\right) 35.4 / 2.28$ & $\left(\mathrm{~W}^{6+}\right) 37.5 / 2.28$ \\
\hline $\mathrm{PW}_{12} / \mathrm{TiO}_{2}$ exA & $\mathrm{Ti}_{23.7} \mathrm{O}_{73.5} \mathrm{~W}_{2.4} \mathrm{P}_{0.3}$ & 0.10 & - & - \\
\hline $\mathrm{PW}_{12} / \mathrm{ZrO}_{2}$ exA & $\mathrm{Zr}_{18.3} \mathrm{O}_{74.9} \mathrm{~W}_{3.9} \mathrm{P}_{2.9}$ & 0.21 & $\left(\mathrm{~W}^{6+}\right) 36.0 / 1.90$ & $\left(\mathrm{~W}^{6+}\right) 38.1 / 1.90$ \\
\hline
\end{tabular}

${ }^{\mathrm{a} X}$ indicates $\mathrm{Si}$, Ti or $\mathrm{Zr}$

Although the deconvolution of the $\mathrm{W} 4 \mathrm{f}$ spectrum of the $\mathrm{PW}_{12} / \mathrm{SiO}_{2}$ exA sample showed that the position of the maxima and their FWHM values corresponding to the $\mathrm{W} 4 \mathrm{f}_{7 / 2}$ and $\mathrm{W} 4 \mathrm{f}_{5 / 2}$ remained unchanged compared to the materials obtained under other deposition methods, one can observe the appearance of another peak at about $39.2 \mathrm{eV}$, which can be assigned to the decomposed $\mathrm{PW}_{12}$ (Figure 4(B)). The $\mathrm{W} 4 \mathrm{f}$ spectrum of the $\mathrm{PW}_{12} / \mathrm{TiO}_{2}$ exA showed very broad maxima with low intensities owing to a relatively low surface content of $\mathrm{W}$ species. The appearance of the shoulder at about $41 \mathrm{eV}$ on the spectrum can be attributed to the degraded HPA as the result of the reaction with titanium isopropoxide under hydrothermal conditions (Figure 4(B)). The XPS W 4f spectrum of the zirconia-supported HPA did not show the same features as that of the above described metal oxides. Nonetheless, a significant displacement of the maxima to $36.0 \mathrm{eV}\left(\mathrm{W}_{4} \mathrm{f}_{7 / 2}\right)$ and 38.1 $\mathrm{eV}\left(\mathrm{W}_{4} \mathrm{f}_{5 / 2}\right.$ ) indicates on the changes in the state of tungsten in the $\mathrm{PW}_{12}$ units (Figure 4(B), Table 2). The shift of the $\mathrm{BE}$ to higher values can be related to the withdrawal of electron density from the W of HPA owing to its reaction with $\mathrm{ZrO}_{2}$ species.

\subsection{XAS characterization of the supported HPAs}

\subsubsection{XANES study}

XAS analysis of structures based on $\mathrm{W}$ at $\mathrm{L}_{3}(10207 \mathrm{eV})$ and $\mathrm{L}_{1}(12100 \mathrm{eV})$ absorption edge allowed to obtain structural information about the coordination, valence and symmetry of $\mathrm{W}$ species depending on the methodology preparation of HPAs and the type of supports. Figure 5(A) and (B) show XANES measurements performed at the $\mathrm{W} \mathrm{L}_{3}$ and $\mathrm{L}_{1}$-edge respectively for all of the HPAs unsupported and supported binary materials under study.
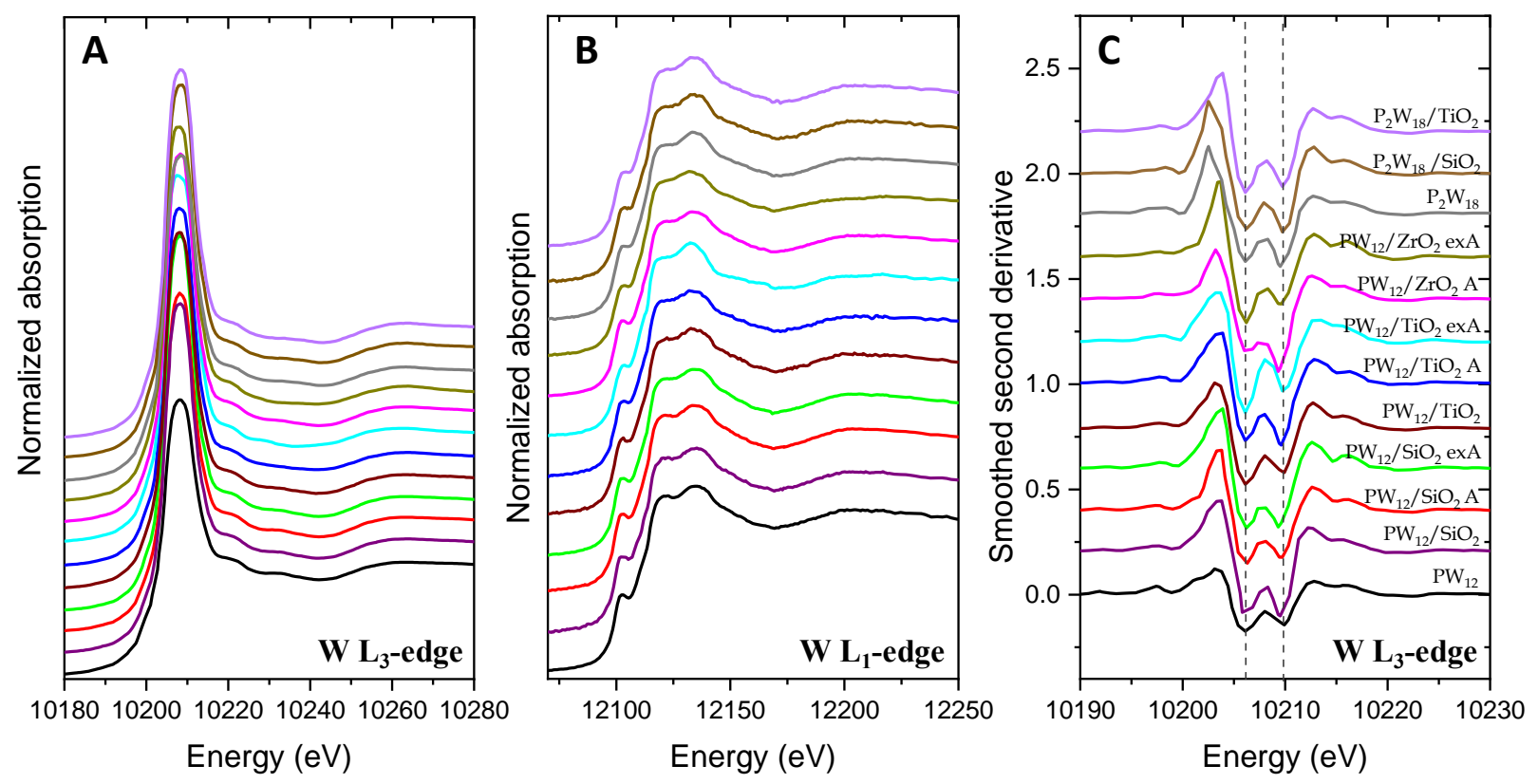

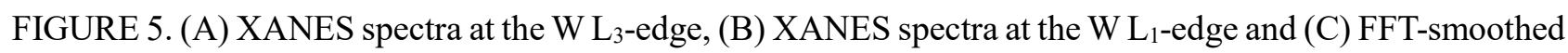
second derivative curves of whiteline at the $\mathrm{W} \mathrm{L}_{3}$-edge for all of the HPAs, both pristine and supported. 
Samples from bottom to top: $\mathrm{PW}_{12}, \mathrm{PW}_{12} / \mathrm{SiO}_{2}, \mathrm{PW}_{12} / \mathrm{SiO}_{2} \mathrm{~A}, \mathrm{PW}_{12} / \mathrm{SiO}_{2}$ exA, $\mathrm{PW}_{12} / \mathrm{TiO}_{2}, \mathrm{PW}_{12} / \mathrm{TiO}_{2} \mathrm{~A}$, $\mathrm{PW}_{12} / \mathrm{TiO}_{2}$ exA, $\mathrm{PW}_{12} / \mathrm{ZrO}_{2} \mathrm{~A}, \mathrm{PW}_{12} / \mathrm{ZrO}_{2}$ exA, $\mathrm{P}_{2} \mathrm{~W}_{18}, \mathrm{P}_{2} \mathrm{~W}_{18} / \mathrm{SiO}_{2}$ and $\mathrm{P}_{2} \mathrm{~W}_{18} / \mathrm{TiO}_{2}$ as labelled in panel C.

XANES spectra at the $\mathrm{W} \mathrm{L}_{3}$-edge present a whiteline associated with the photoelectron transition from the core level $2 p_{3 / 2}$ to the level $5 \mathrm{~d}$. At this absorption edge, the final states are energetically and spatially more localized than at the $L_{1}$ absorption edge, consequently showing an intense transition peak. This main peak, i.e. the whiteline, is clearly identified and its shape depends on the particular structure. The differences between the XANES spectra collected from the samples regard the amplitude and width on the whiteline. The differences at the whiteline shape could be interpreted by considering the splitting of the $5 \mathrm{~d}$ state by the ligand field, which are the $t_{2 \mathrm{~g}}$ and $\mathrm{e}_{\mathrm{g}}$ orbitals. The octahedron or the structural distortion of the octahedral symmetry is known to lead a large shift of $5 \mathrm{~d}$ states than the tetrahedral $\mathrm{W}$ structures. A possible way to analyse the splitting of the final state of the $5 \mathrm{~d}$ orbitals from the $\mathrm{W} \mathrm{L}_{3}$-whiteline is through the second derivate spectra of the $\mathrm{W} \mathrm{L}_{3}$-edges, shown in Figure 5(C). A splitting of the states is clearly observed for all of the samples and the energy gap between both states is related directly to the d orbital splitting. The split values for the structures containing $\mathrm{W}$ studied in this work are all very similar, about 3.2-3.6 eV (see Table 3), and a lower energy gap could be associated with a great distortion of octahedral coordination in $\mathrm{W}$ structures, which is analysed below. On the other hand, the relative absorption intensity between the $t_{2 \mathrm{~g}}$ and $\mathrm{e}_{\mathrm{g}}$ orbitals at the whiteline measured in the $\mathrm{L}_{3}-$ absorption edge can offer information about the tetrahedral and octahedral environment of the $\mathrm{W}$ species. In order to analyse it, XANES spectra at the $\mathrm{L}_{3}$ whiteline were deconvoluted representing each electron transition ( $\mathrm{t}_{2 \mathrm{~g}}$ and $\mathrm{e}_{\mathrm{g}}$ ) to vacant $5 \mathrm{~d}$ orbitals by a Lorentz function and the vacuum level by an arctangent one, which was the same for all the spectra. Analysis was similar to that carried out by other authors $[22,35,36]$. The area ratios obtained between the peak at lower energy related to the $t_{2 g}$ orbital and the peak at larger energy attributed to the $\mathrm{e}_{\mathrm{g}}$ orbital $\left(\mathrm{t}_{2 \mathrm{~g}}: \mathrm{e}_{\mathrm{g}}\right)$ were around 1.5. This value corresponds to octahedral W structures like those of the HPAs analysed in this work.

As far as concern the total absorption intensity of the whiteline, obtained from the sum of the areas of peaks related to $t_{2 \mathrm{~g}}$ and $\mathrm{e}_{\mathrm{g}}$ orbitals, we have found that the values are not the same for all of the samples under study, and depend on the $\mathrm{W}$ structure. Indeed, the intensity is related to the density of the unoccupied states of symmetry and the stereochemical arrangement of neighbours around the absorbing atoms [37]. As a consequence, the higher is the oxidation state of the compound, the higher is the whiteline. One factor that may induce a change at the whiteline is the covalence of the bonds. If that covalence is enhanced, the probability of $2 p \rightarrow 5 d$ transition is likely to increase due to screening effects on the electronic transitions. Besides, multiple scattering processes should be considered in the whiteline intensity. Specifically, S. Yamazoe et al. [21] presented a XAS study in $\mathrm{W}$ species and evidenced that the whiteline intensity at the $\mathrm{W} \mathrm{L}_{3}$-edge shows a linear behaviour with the pre-edge area of the $\mathrm{W} \mathrm{L}_{1}$-edge, relating the whiteline intensity with the structure of the W species. However, in our work, there is no clear trend for the samples under study, therefore other effects should be considered to explain the variations in the whiteline intensity at the $\mathrm{W} \mathrm{L}_{3}$-edge.

XANES spectra at the $\mathrm{W} \mathrm{L}_{1}$-edge show similar characteristics for all samples (see Figure 5(B)), such as the small pre-peak around $12102 \mathrm{eV}$, attributed to forbidden $2 \mathrm{~s} \rightarrow 5 \mathrm{~d}$ electron transitions. This peak is a typical signature of non-centrosymmetric sites and it has a linear relationship with the split in the $5 \mathrm{~d}$ orbital. The intensity of that pre-peak can be related to a distortion in the W octahedron of the HPA sample under study. In order to obtain a more detailed analysis, a deconvolution of the pre-edge was carried out with a Lorentz function and an arctangent function at the same way than for the $\mathrm{L}_{3}$-edge. Concerning the position of the absorption edge, it was the same for all samples indicating the same valence of $\mathrm{W}$ atoms $\left(\mathrm{W}^{6+}\right)$, and so the

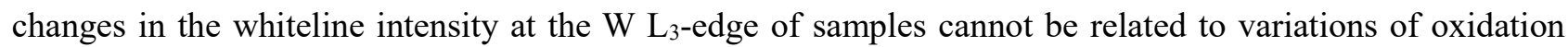
state. The most relevant results obtained from the analysis of spectra deconvolution both at $\mathrm{W}_{3}$ and $\mathrm{L}_{1}$ - edge are summarised in Table 3. 
TABLE 3. Results obtained from the spectra deconvolution both at $\mathrm{L}_{3}$-edge and $\mathrm{L}_{1}$ - edge for all samples: sum of peak areas at the $\mathrm{L}_{3}$-edge whiteline, energy gap of the split $5 \mathrm{~d}$ states at $\mathrm{W} \mathrm{L}_{3}$-edge XANES and area pre-

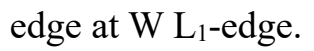

\begin{tabular}{|l|c|c|c|}
\hline Sample & $\begin{array}{c}\text { Sum of peak areas } \\
\text { at the } \mathrm{L}_{3} \text { whiteline }\end{array}$ & $\begin{array}{c}\text { Energy gap of the split 5d } \\
\text { states at } \mathrm{W} \mathrm{L}_{3} \text { edge XANES } \\
(\mathrm{eV})\end{array}$ & $\begin{array}{c}\text { Area pre-edge at } \\
\mathrm{W}_{\text {L }} \text {-edge }\end{array}$ \\
\hline $\mathrm{PW}_{12}$ & $25.8(4)$ & $3.68(6)$ & $2.87(3)$ \\
\hline $\mathrm{P}_{2} \mathrm{~W}_{18}$ & $29.3(3)$ & $3.67(4)$ & $2.56(3)$ \\
\hline $\mathrm{PW}_{12} / \mathrm{SiO}_{2}$ & $30.6(5)$ & $3.42(4)$ & $2.86(3)$ \\
\hline $\mathrm{PW}_{12} / \mathrm{TiO}_{2}$ & $31.1(4)$ & $3.38(6)$ & $2.82(3)$ \\
\hline $\mathrm{P}_{2} \mathrm{~W}_{18} / \mathrm{SiO}_{2}$ & $32.7(3)$ & $3.44(6)$ & $2.62(3)$ \\
\hline $\mathrm{P}_{2} \mathrm{~W}_{18} / \mathrm{TiO}_{2}$ & $32.3(2)$ & $3.66(4)$ & $2.62(3)$ \\
\hline $\mathrm{PW}_{12} / \mathrm{SiO}_{2} \mathrm{~A}$ & $29.5(5)$ & $3.21(4)$ & $2.87(3)$ \\
\hline $\mathrm{PW}_{12} / \mathrm{TiO}_{2} \mathrm{~A}$ & $31.2(4)$ & $3.39(6)$ & $2.69(3)$ \\
\hline $\mathrm{PW}_{12} / \mathrm{ZrO}_{2} \mathrm{~A}$ & $31.8(4)$ & $2.99(6)$ & $2.75(3)$ \\
\hline $\mathrm{PW}_{12} / \mathrm{SiO}_{2}$ exA & $32.0(5)$ & $3.20(4)$ & $2.90(3)$ \\
\hline $\mathrm{PW}_{12} / \mathrm{TiO}_{2}$ exA & $32.7(3)$ & $3.94(4)$ & $2.37(3)$ \\
\hline $\mathrm{PW}_{12} / \mathrm{ZrO}_{2}$ exA & $33.1(4)$ & $3.38(4)$ & $2.45(3)$ \\
\hline
\end{tabular}

\subsubsection{XANES analysis of Keggin $P_{12}$ and Wells-Dawson $\mathrm{P}_{2} \mathrm{~W}_{18}$ on commercial $\mathrm{SiO}_{2}$ and $\mathrm{TiO}_{2}$}

XANES spectra measured at $\mathrm{W} \mathrm{L}_{3}$ and $\mathrm{L}_{1}$-edge for the pristine $\mathrm{PW}_{12}$ and $\mathrm{P}_{2} \mathrm{~W}_{18}$, and for the binary materials where the $\mathrm{PW}_{12}$ and $\mathrm{P}_{2} \mathrm{~W}_{18}$ were supported on commercial $\mathrm{SiO}_{2}$ and $\mathrm{TiO}_{2}$ are presented in Figure 6. The most visible effect induced in the samples where $\mathrm{PW}_{12}$ was supported on the oxides is the increase of the whiteline

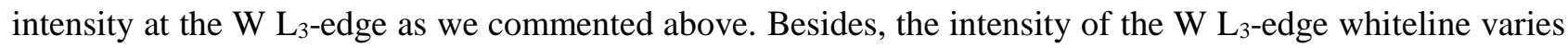
depending on the type of oxide employed as support, being lower for the $\mathrm{SiO}_{2}$-supported $\mathrm{PW}_{12}$ and higher for the $\mathrm{TiO}_{2}$-supported $\mathrm{PW}_{12}$, as observed in Figure 6(A). A slight decrease of the energy gap in split of the 5d orbital (within the error) is noted in the supported $\mathrm{PW}_{12}$ (see Figure 6(E)).

Comparing the pristine Keggin $\left(\mathrm{PW}_{12}\right)$ and Wells-Dawson $\left(\mathrm{P}_{2} \mathrm{~W}_{18}\right)$ heteropolyacid structures, it is observed a highest intensity of the whiteline at the $\mathrm{W} \mathrm{L}_{3}$-edge for the structure $\mathrm{P}_{2} \mathrm{~W}_{18}$ (see Figure 6(B)). Besides, the incorporation of the $\mathrm{P}_{2} \mathrm{~W}_{18}$ structures onto the oxide supports induces an increase of the whiteline intensity, being slightly higher for sample supported on $\mathrm{SiO}_{2}$. Possible explications of these modifications of the whiteline intensity may be related to variations of octahedral $\mathrm{W}$ species (intensity of pre-peak at the $\mathrm{L}_{1}$-edge). It is observed for the case of pristine $\mathrm{P}_{2} \mathrm{~W}_{18}$ clusters where the pre-peak at the $\mathrm{L}_{1}$-edge decreases with respect to the pristine $\mathrm{PW}_{12}$ structure, indicating a larger coordination of the $\mathrm{W}$ species. For species supported on oxides, the changes are slight and other possible explanations must be considered, Figure 6(C-D).

As far as the energy gap between the $\mathrm{t}_{2 \mathrm{~g}}$ and $\mathrm{e}_{\mathrm{g}}$ orbitals at the $\mathrm{L}_{3}$-absorption edge and the pre-peak area at the W $\mathrm{L}_{1}$-edge is concerned, it is possible to find a relation for some samples: the lower the energy gap in split of the $5 \mathrm{~d}$ orbital, the larger the pre-peak area at the $\mathrm{W} \mathrm{L}_{1}$-edge and therefore the octahedral distortion of $\mathrm{W}$ structures (Table 3, Figure 6(F) and $(\mathrm{H})$ ). Specifically, a lower distortion in the octahedron was found for the pristine $\mathrm{P}_{2} \mathrm{~W}_{18}$ structure with respect to the structure of $\mathrm{PW}_{12}$. By comparing the pristine structures with those supported on $\mathrm{SiO}_{2}$ or $\mathrm{TiO}_{2}$, no significant variations have been observed in the $\mathrm{W}$ octahedron. Only for the $\mathrm{P}_{2} \mathrm{~W}_{18}$ supported on $\mathrm{SiO}_{2}$ a lower value of the energy gap in split of the 5d orbital is remarkable (see Figure $6(\mathrm{~F}))$. 

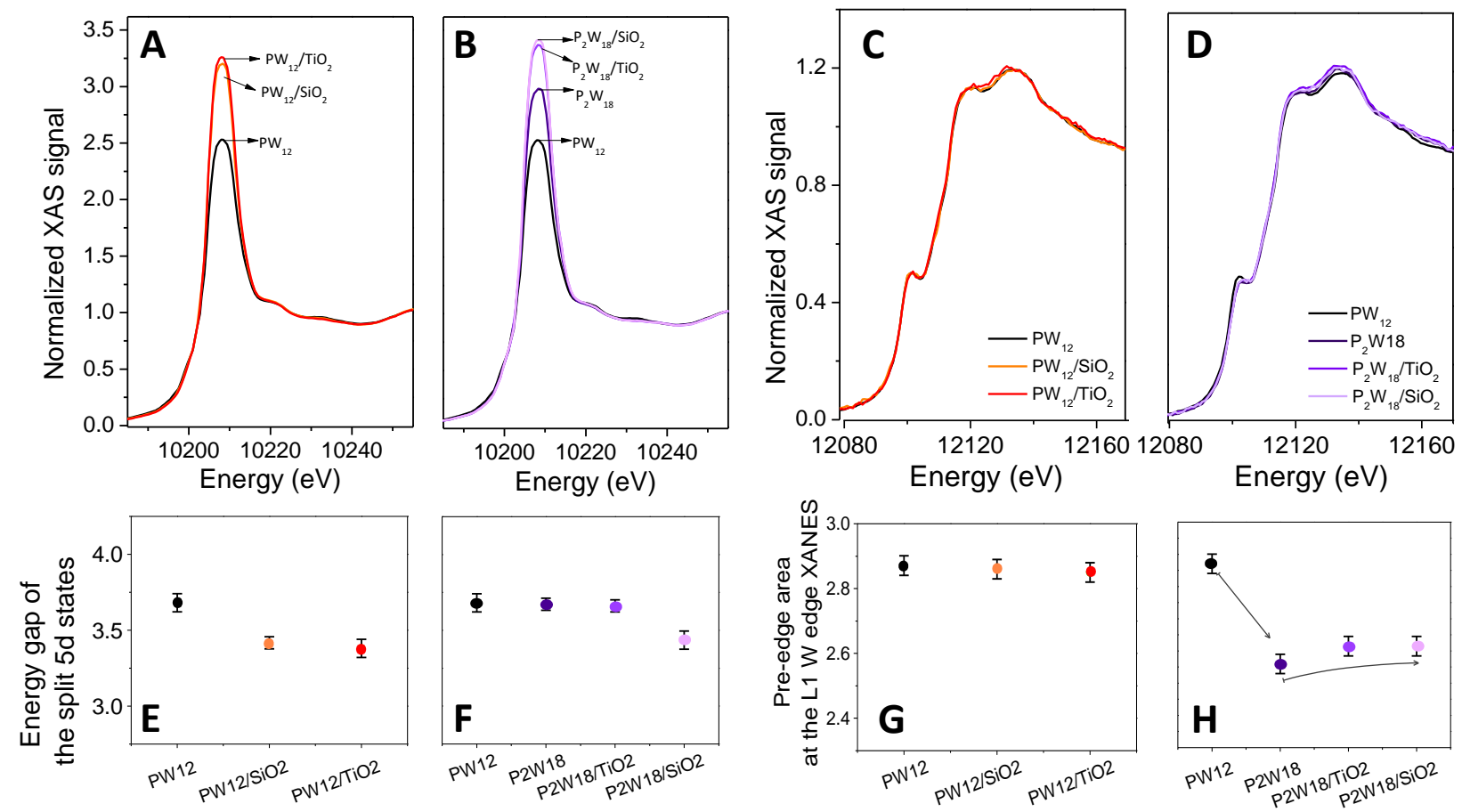

Sample

Sample

Sample

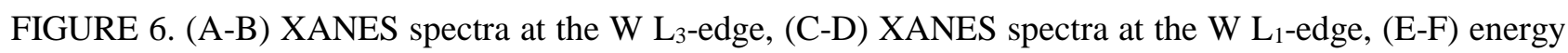
gap of the split $5 \mathrm{~d}$ state in $\mathrm{W} \mathrm{L}_{3}$-edge whiteline and $(\mathrm{G}-\mathrm{H})$ pre-edge area at the $\mathrm{W}_{1}$-edge for the Keggin structures: $\mathrm{PW}_{12}, \mathrm{PW}_{12} / \mathrm{SiO}_{2}$ and $\mathrm{PW}_{12} / \mathrm{TiO}_{2}$ and the Wells-Dawson heteropolytungstates: $\mathrm{P}_{2} \mathrm{~W}_{18}, \mathrm{P}_{2} \mathrm{~W}_{18} / \mathrm{SiO}_{2}$ and $\mathrm{P}_{2} \mathrm{~W}_{18} / \mathrm{TiO}_{2}$

\subsubsection{XANES analysis of Keggin PW 12 on different types of oxides prepared by home routes: $\mathrm{SiO}_{2}, \mathrm{TiO}_{2}$, and $\mathrm{ZrO}_{2}$}

XANES spectra obtained at $\mathrm{W} \mathrm{L}_{3}$ and $\mathrm{L}_{1}$-edge for the pristine $\mathrm{PW}_{12}$ and for the binary material where the $\mathrm{PW}_{12}$ was supported on $\mathrm{SiO}_{2}, \mathrm{TiO}_{2}$ and $\mathrm{ZrO}_{2}$ prepared from the alkoxides (A methodology) and by the solvothermal procedure (exA) are shown in Figure 7.

The most visible effect induced in the samples where $\mathrm{PW}_{12}$ was supported on the oxides is the increase of the whiteline intensity at the $\mathrm{W} \mathrm{L}_{3}$-edge, as we identified in the $\mathrm{PW}_{12}$ prepared on commercial oxides (see Figure 6). The intensity increase is higher for the samples prepared by the solvothermal process (Figure 7(E) and Table 3). Besides, the area of the $\mathrm{W} \mathrm{L}_{3}$-edge whiteline varies depending on the type of oxide employed as support, being lower for the $\mathrm{PW}_{12}$ supported on $\mathrm{SiO}_{2}$ and higher for the $\mathrm{PW}_{12}$ supported on $\mathrm{ZrO}_{2}$, as Figure 7(A-B) shows. Possible explanations for the whiteline intensity are presented in the following. For the case of the samples supported on $\mathrm{ZrO}_{2}$ and $\mathrm{TiO}_{2}$ the whiteline intensity can be related to an increase of coordination for the $\mathrm{W}$ species (decrease of pre-peak at the $\mathrm{L}_{1}$-edge), while for $\mathrm{PW}_{12}$ clusters supported on $\mathrm{SiO}_{2}$ the effects are light and other possible explanations must be considered, Figure 7(C, D and G).

As far as the energy gap between the $\mathrm{t}_{2 \mathrm{~g}}$ and $\mathrm{e}_{\mathrm{g}}$ orbitals at the $\mathrm{L}_{3}$-absorption edge is concerned (see Figure 7(F)), the values are lower for the $\mathrm{PW}_{12}$ structures supported on $\mathrm{ZrO}_{2}$ and higher for those on $\mathrm{TiO}_{2}$. Moreover, it is possible to note an increase of the energy gap when samples were prepared solvothermally with $\mathrm{ZrO}_{2}$ and $\mathrm{TiO}_{2}$, whereas the behaviour is opposite for the $\mathrm{SiO}_{2}$. These results can be related to pre-peak area at the $\mathrm{W} \mathrm{L}_{1}-$ edge, (Figure $7(\mathrm{G})$ ), indicating a higher coordination of $\mathrm{PW}_{12}$ clusters prepared by the solvothermal methodology (exA) for the case of the $\mathrm{TiO}_{2}$ and $\mathrm{ZrO}_{2}$ supports. These results could be related to the incorporation of the $\mathrm{Ti}$ and $\mathrm{Zr}$ species into the $\mathrm{PW}_{12}$ clusters, taking into account the changes in the shape of XANES region and as reported below by EXAFS measurements. 

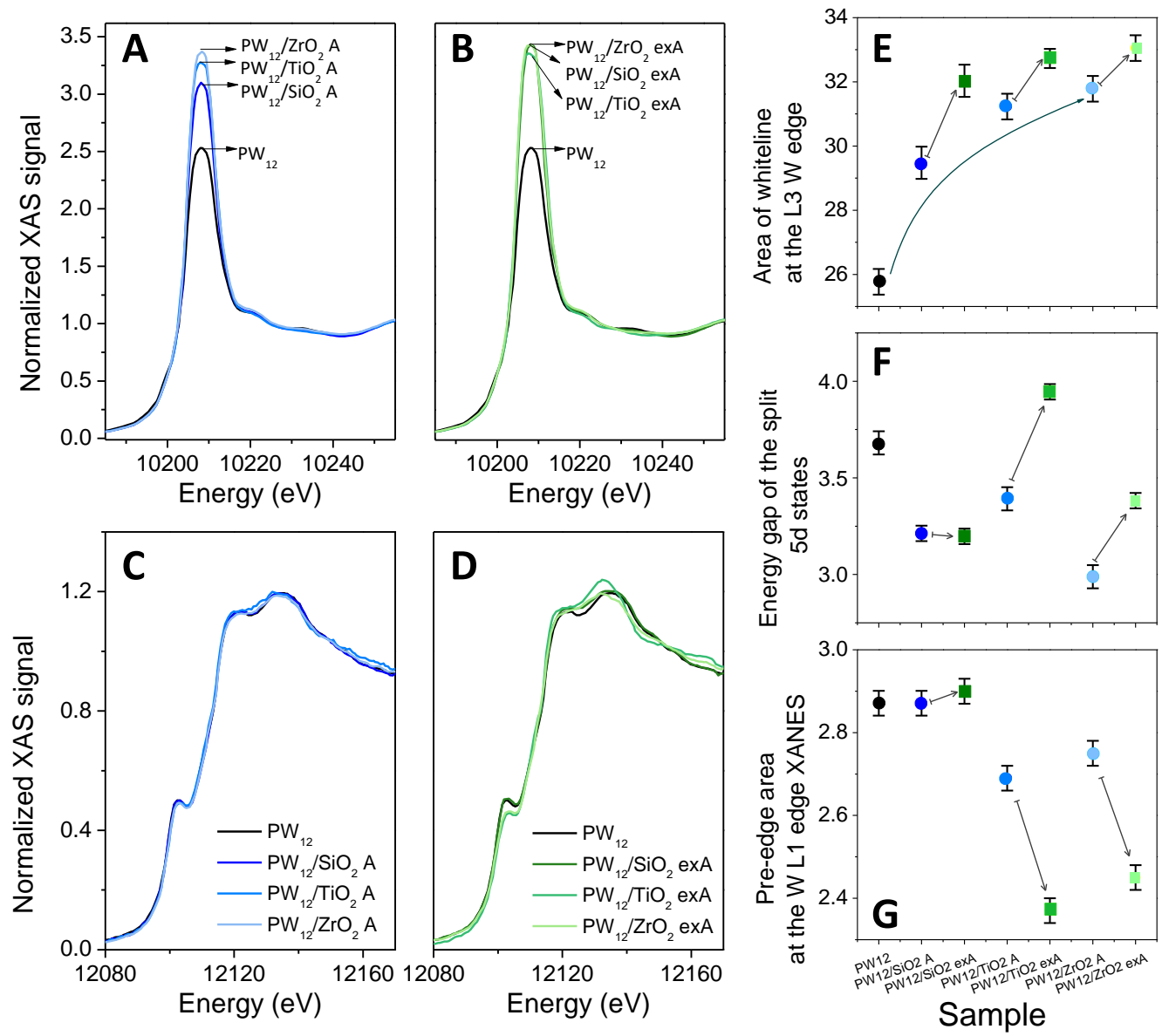

FIGURE 7. (A-B) XANES spectra at the $\mathrm{W} \mathrm{L}_{3}$-edge, (C-D) XANES spectra at the $\mathrm{W} \mathrm{L}_{1}$-edge, (E) total area at the $\mathrm{W} \mathrm{L}_{3}$-edge whiteline, (F) energy gap of the split $5 \mathrm{~d}$ state at $\mathrm{W} \mathrm{L}_{3}$-edge whiteline and $(\mathrm{G})$ pre-edge area at the $\mathrm{W} \mathrm{L}_{1}$-edge for sample $\mathrm{PW}_{12}, \mathrm{PW}_{12} / \mathrm{SiO}_{2} \mathrm{~A}, \mathrm{PW}_{12} / \mathrm{SiO}_{2}$ exA, $\mathrm{PW}_{12} / \mathrm{TiO}_{2} \mathrm{~A}, \mathrm{PW}_{12} / \mathrm{TiO}_{2}$ exA, $\mathrm{PW}_{12} / \mathrm{ZrO}_{2}$ $\mathrm{A}$ and $\mathrm{PW} / 2 / \mathrm{ZrO}_{2}$ exA.

A comparative analysis of the XANES results obtained at $\mathrm{W} \mathrm{L}_{3}$ and $\mathrm{L}_{1}$-edge for the $\mathrm{PW}_{12}$ structures supported on $\mathrm{SiO}_{2}$ and $\mathrm{TiO}_{2}$ prepared by the three different routes (impregnation on the commercial, the home prepared oxide (A) and solvothermal procedure (exA)) was performed. Concerning the energy gap between the $t_{2 g}$ and $\mathrm{e}_{\mathrm{g}}$ orbitals at the $\mathrm{L}_{3}$-absorption edge, we observe the following trend: values of energy gap change according to $\mathrm{PW}_{12} / \mathrm{SiO}_{2}>\mathrm{PW}_{12} / \mathrm{SiO}_{2} \mathrm{~A}>\mathrm{PW}_{12} / \mathrm{SiO}_{2}$ exA (see Table 3 ). These results can be associated with the pre-peak area at the $\mathrm{W} \mathrm{L}_{1}$-edge that slightly increases as the energy gap of the split in the $5 \mathrm{~d}$ orbital decreases (Table 3 ) indicating an octahedral distortion of $\mathrm{PW}_{12}$ clusters prepared by exA methodology and that is lower for the $\mathrm{PW}_{12}$ clusters prepared by impregnation.

On the other hand, $\mathrm{PW}_{12}$ structures supported on $\mathrm{TiO}_{2}$ show an opposite trend than for $\mathrm{PW}_{12}$ prepared on $\mathrm{SiO}_{2}$. The pre-peak area at the $\mathrm{W} \mathrm{L}_{1}$-edge is lower for sample $\mathrm{PW}_{12} / \mathrm{TiO}_{2}$ exA and higher for sample $\mathrm{PW}_{12} / \mathrm{TiO}_{2}$, indicating a larger number of octahedral $\mathrm{W}$ species for $\mathrm{PW}_{12}$ clusters prepared by exA technique and lower for $\mathrm{PW}_{12}$ clusters prepared by impregnation. Similar behaviour is noted for $\mathrm{HPAs}$ supported on $\mathrm{ZrO}_{2}$. These results are in agreement with the values obtained of the energy gap of the split in the $5 \mathrm{~d}$ orbital (see Table 3 ).

One can suggest that the apparent reason for the above mentioned observations is the nature of oxide supports. More basic character of $\mathrm{TiO}_{2}$ promotes stronger interaction with acidic $\mathrm{PW}_{12}$ species which could lead to the destruction of a characteristic $\mathrm{W}$ arrangement in the cluster. Silica, on the other hand, only accommodates the increasing amounts of HPA inside its porous structure in the order $\mathrm{PW}_{12} / \mathrm{SiO}_{2}>\mathrm{PW}_{12} / \mathrm{SiO}_{2} \mathrm{~A}>\mathrm{PW}_{12} / \mathrm{SiO}_{2}$ exA avoiding strong acid-base interaction.

\subsubsection{EXAFS study of the supported HPAs}


EXAFS analysis was also performed at the $\mathrm{W} \mathrm{L}_{3}$-edge for all of the samples and the $\mathrm{R}$ fitting was carried out in the range of the first W-O shell between 1 and $2.1 \AA$, in order to study the local structure around the W absorbing atom. The Fourier Transform (FT) was carried out in the $k^{3} \chi(k)$ weighted EXAFS signal between 2.7 and $10.5 \AA^{-1}$. All samples were fitted with two W-O distances at the first shell whose bond length is different. Obtained EXAFS parameters are shown in Table 4. For the fitting, the shift at the edge energy $E_{0}$ was calculated for the pure $\mathrm{PW}_{12}$ structure and was fixed for the rest of samples.

TABLE 4. First neighbour parameters obtained from the fitting of the FT of the EXAFS signal. N1 and N2: coordination number, R1 and R2: interatomic distance, $\sigma(1)^{2}$ and $\sigma(2)^{2}$ : Debye- Waller factor. The FT was carried out in the $k^{3} \chi(k)$ weighted EXAFS signal between 2.7 and $10.5 \AA^{-1}$.

\begin{tabular}{|l|l|l|l|l|l|l|}
\hline Sample & $\mathrm{N} 1$ & $\mathrm{R} 1(\AA)$ & $\sigma(1)^{2}\left(\AA^{2}\right)$ & $\mathrm{N} 2$ & $\mathrm{R} 2(\AA)$ & $\sigma(2)^{2}\left(\AA^{2}\right)$ \\
\hline $\mathrm{PW}_{12}$ & 1.0 & $1.732(7)$ & $0.007(1)$ & 4.0 & $2.184(2)$ & $0.006(3)$ \\
\hline $\mathrm{P}_{2} \mathrm{~W}_{18}$ & $1.3(3)$ & $1.723(6)$ & $0.008(1)$ & $3.4(4)$ & $2.178(3)$ & $0.005(1)$ \\
\hline $\mathrm{PW}_{12} / \mathrm{SiO}_{2}$ & $1.3(1)$ & $1.740(5)$ & $0.009(1)$ & $4.4(1)$ & $2.178(1)$ & $0.006(1)$ \\
\hline $\mathrm{PW}_{12} / \mathrm{TiO}_{2}$ & $1.1(1)$ & $1.728(5)$ & $0.009(1)$ & $3.6(1)$ & $2.184(2)$ & $0.006(1)$ \\
\hline $\mathrm{P}_{2} \mathrm{~W}_{18} / \mathrm{SiO}_{2}$ & $1.3(5)$ & $1.729(9)$ & $0.009(2)$ & $4.9(4)$ & $2.180(5)$ & $0.007(1)$ \\
\hline $\mathrm{P}_{2} \mathrm{~W}_{18} / \mathrm{TiO}_{2}$ & $1.5(5)$ & $1.735(9)$ & $0.009(2)$ & $4.5(3)$ & $2.177(4)$ & $0.007(1)$ \\
\hline $\mathrm{PW}_{12} / \mathrm{SiO}_{2} \mathrm{~A}$ & $1.2(1)$ & $1.734(5)$ & $0.008(1)$ & $4.3(1)$ & $2.187(2)$ & $0.005(1)$ \\
\hline $\mathrm{PW}_{12} / \mathrm{TiO}_{2} \mathrm{~A}$ & $3.1(2)$ & $1.738(5)$ & $0.014(1)$ & $3.6(2)$ & $2.160(4)$ & $0.010(1)$ \\
\hline $\mathrm{PW}_{12} / \mathrm{ZrO}_{2} \mathrm{~A}$ & $2.9(1)$ & $1.722(3)$ & $0.013(1)$ & $3.4(1)$ & $2.179(2)$ & $0.006(1)$ \\
\hline $\mathrm{PW}_{12} / \mathrm{SiO}_{2}$ exA & $1.3(1)$ & $1.734(6)$ & $0.009(1)$ & $4.9(1)$ & $2.189(2)$ & $0.006(1)$ \\
\hline $\mathrm{PW}_{12} / \mathrm{TiO}_{2}$ exA & $3.8(2)$ & $1.732(4)$ & $0.011(1)$ & $1.2(2)$ & $2.121(9)$ & $0.006(1)$ \\
\hline $\mathrm{PW}_{12} / \mathrm{ZrO}_{2}$ exA & $4.4(5)$ & $1.714(5)$ & $0.012(1)$ & $3.8(2)$ & $2.091(8)$ & $0.090(1)$ \\
\hline
\end{tabular}

\subsubsection{EXAFS analysis of Keggin $\mathrm{PW}_{12}$ and Wells-Dawson $\mathrm{P}_{2} \mathrm{~W}_{18}$ on commercial $\mathrm{SiO}_{2}$ and $\mathrm{TiO}_{2}$}

The FT of the EXAFS signal for the pristine $\mathrm{PW}_{12}$ and $\mathrm{P}_{2} \mathrm{~W}_{18}$ structures and those supported on commercial oxides $\mathrm{SiO}_{2}$ and $\mathrm{TiO}_{2}$ are reported in Figure 8. In both type of structures, a similar profile at the $\mathrm{R}$ space is obtained.

Figure 8(A) shows the EXAFS signals obtained for the pure $\mathrm{PW}_{12}$ structure and that prepared on $\mathrm{SiO}_{2}$ and $\mathrm{TiO}_{2}$. The $\mathrm{PW}_{12}$ structure supported on $\mathrm{SiO}_{2}$ presents an increase of the coordination number in both W-O shells, an elongation of the W-O bond length at the first shell and a shortening of the second one (Table 4). On the other hand, for the samples supported on $\mathrm{TiO}_{2}$ shows a coordination decrease at the second shell distance and a shortening of the W-O bond length at the first coordination shell. With respect to the Debye-Waller (DW) factors, an increase is obtained for HPAs supported at the first neighbours, which may indicate a large structural disorder although the octahedral distortions of the structure observed by XANES are not notable.

The pristine $\mathrm{P}_{2} \mathrm{~W}_{18}$ cluster structure shows a similar profile at the $\mathrm{R}$ space than that of the bare $\mathrm{PW}_{12}$, as shown in Figure 8(B). The most significant changes in the $\mathrm{P}_{2} \mathrm{~W}_{18}$ structure are related to the relative intensity of the two W-O shells. From the fitting of the FT of the EXAFS signal, an increase of the coordination number in the first W-O shell and a decrease in the second one (see Table 4) are obtained. Moreover, a reduction of the bond lengths in $\mathrm{W}-\mathrm{O}$ shells was observed with respect to the $\mathrm{PW}_{12}$ structure. As far as the D-W factors are concerned, we cannot appreciate significant modifications related to the structural disorder.

As $\mathrm{P}_{2} \mathrm{~W}_{18}$ structure is supported on $\mathrm{SiO}_{2}$ and $\mathrm{TiO}_{2}$, small modifications at the $\mathrm{R}$ space, as shown in Figure 8(B), have been observed: a slight increase at the first $\mathrm{W}-\mathrm{O}$ shell is found for the $\mathrm{P}_{2} \mathrm{~W}_{18}$ supported on $\mathrm{SiO}_{2}$, which rises for that prepared on $\mathrm{TiO}_{2}$. The most appreciable changes have been found in the relative intensity of the two W-O shells as the Wells-Dawson structures are supported on the metal oxides. An increase of the coordination number at the second $\mathrm{W}-\mathrm{O}$ shell was found, being higher for sample supported on $\mathrm{SiO}_{2}$. $\mathrm{Besides}_{\text {, }}$ at the first W-O shell an increase for $\mathrm{P}_{2} \mathrm{~W}_{18}$ structure supported on $\mathrm{TiO}_{2}$ is also noted (taking into account that 
these variations are within the fitting error). As far as the D-W factor is concerned, we find a trend to increase for $\mathrm{P}_{2} \mathrm{~W}_{18}$ supported with respect to the bare HPA (clearer at the second shell), which may be related to an increase of the structural distortion of the $\mathrm{P}_{2} \mathrm{~W}_{18}$ cluster in these binary materials.
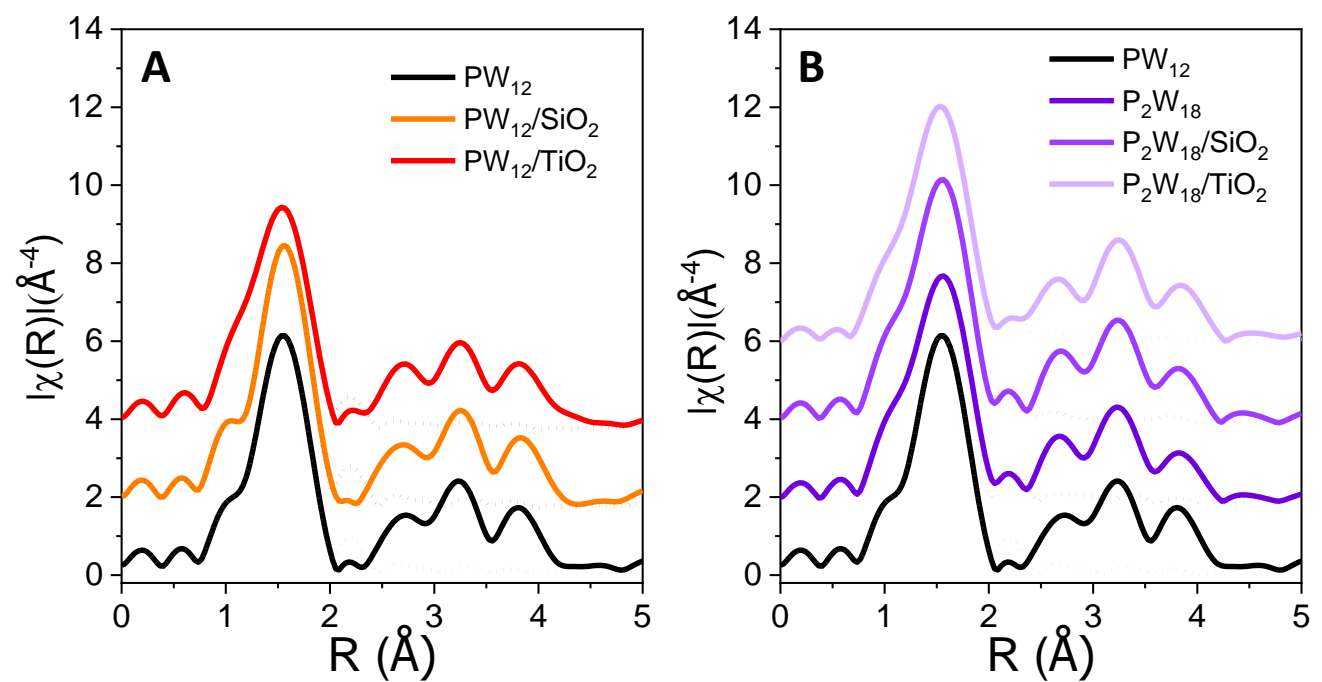

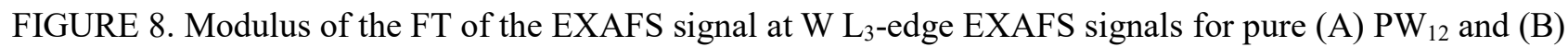
$\mathrm{P}_{2} \mathrm{~W}_{18}$ structures and they supported on $\mathrm{SiO}_{2}$ and $\mathrm{TiO}_{2}$ prepared by impregnation on commercial oxides. Continuous lines represent the experimental data and the dots lines show the best-fitting simulations of the first peak.

\subsubsection{EXAFS analysis of Keggin $P_{12}$ on different types of oxides prepared by home routes:} $\mathrm{SiO}_{2}, \mathrm{TiO}_{2}$, and $\mathrm{ZrO}_{2}$

The FT modulus of the EXAFS signal for the pure $\mathrm{PW}_{12}$ and for $\mathrm{PW}_{12}$ supported on several oxides: $\mathrm{SiO}_{2}, \mathrm{TiO}_{2}$, $\mathrm{ZrO}_{2}$, by two preparation routes: impregnation of the home prepared oxide (A) and from solvothermal procedure (exA) is reported in Figure 9
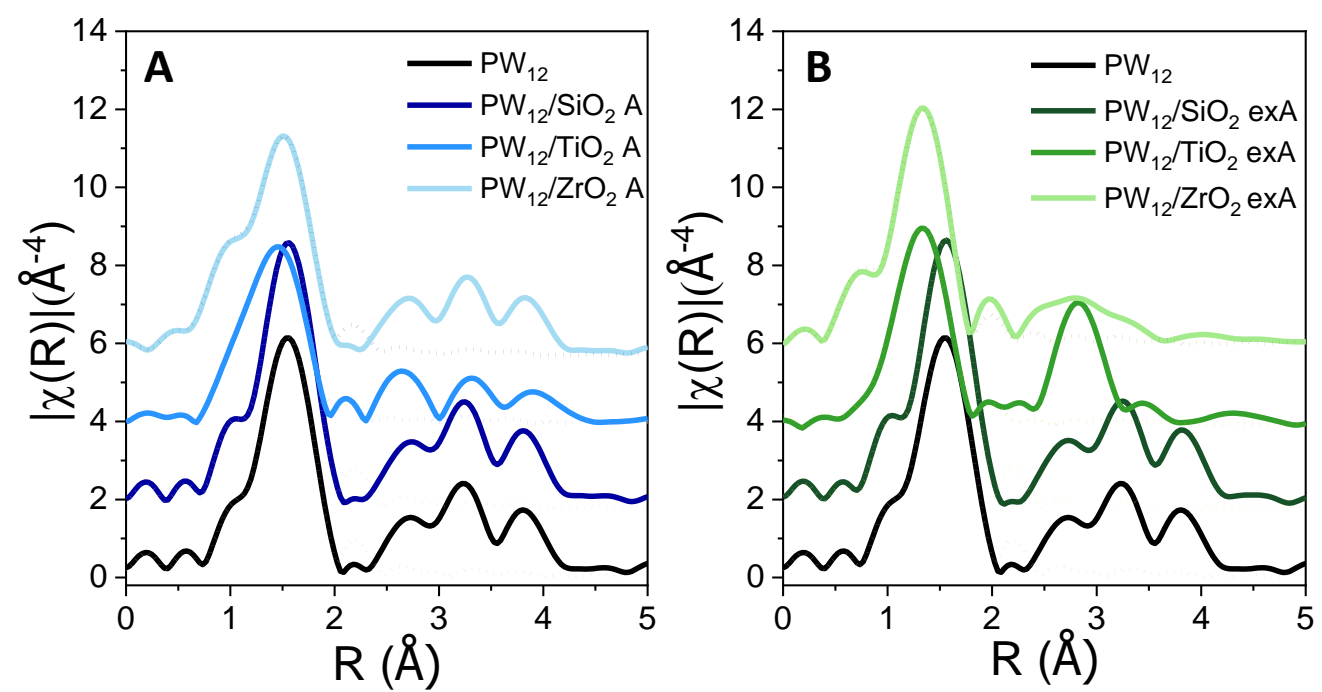

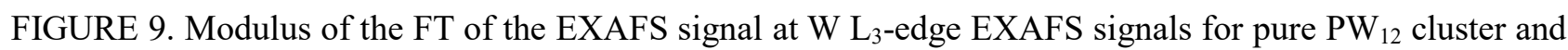
this structure supported on $\mathrm{SiO}_{2}, \mathrm{TiO}_{2}, \mathrm{ZrO}_{2}$ by two preparation routes: (A) A and (B) exA. Continuous lines represent the experimental data and the dots lines show the best-fitting simulations of the first peak. 
The $\mathrm{PW}_{12}$ structure supported on $\mathrm{SiO}_{2}$ presents similar profile at the $\mathrm{R}$ space indifferently from the route of preparation, as shown in Figure 9. An increase of the coordination number in both W-O shells (Table 4) is found for the $\mathrm{PW}_{12}$ clusters supported on $\mathrm{SiO}_{2}$ with respect to the pristine HPA structure, being greater for sample prepared from solvothermal conditions $\mathrm{PW}_{12} / \mathrm{SiO}_{2}$ exA than from the impregnation of the home prepared oxide $\mathrm{PW}_{12} / \mathrm{SiO}_{2} \mathrm{~A}$.

For the samples supported on $\mathrm{TiO}_{2}$, the FT profile of the EXAFS signal shows clear differences depending on the preparation route (see Figure 9). The second W-O distance is shorter as $\mathrm{PW}_{12}$ structure is prepared on $\mathrm{TiO}_{2}$. Besides, sample prepared under solvothermal conditions, $\mathrm{PW}_{12} / \mathrm{TiO}_{2}$ exA, showed a larger shortening of the W-O bond lengths than the $\mathrm{PW}_{12} / \mathrm{TiO}_{2} \mathrm{~A}$. On the other hand, at higher distances we can find a different structure of the local coordination depending on the method employed for the binary material. Specifically, for sample $\mathrm{PW}_{12} / \mathrm{TiO}_{2}$ exA, a coordination shell around $3 \AA$ is clearly identified and possibly corresponds to a shell combining W-Ti and W-W distances as reported by Hilbrig et al. [38] and S. Yamazoe et al. [21] who found it in $\mathrm{WO}_{3} / \mathrm{TiO}_{2}$ catalysts. With respect to the coordination number we observe an increase in the first $\mathrm{W}-\mathrm{O}$ shell and a clear decrease in the second W-O shell, as reported in Table 4.

As far as the $\mathrm{PW}_{12}$ cluster supported on $\mathrm{ZrO}_{2}$ by the two methodologies is concerned, W-O distances decrease for both supported $\mathrm{PW}_{12}$ with respect to the pristine one, being the shortest for the $\mathrm{PW}_{12} / \mathrm{ZrO}_{2}$ exA (see Figure 9). On the other hand, the coordination around $3 \AA$ varies for the sample prepared solvothermally (exA), indicating a modification of the $\mathrm{PW}_{12}$ structure induced, probably, by the incorporation of the $\mathrm{Zr}$ atoms into the structure and generating a W-Zr contribution identified in $\mathrm{WO}_{\mathrm{x}} / \mathrm{TiO}_{2}$ systems as reported by Carrier et al. [23] and Wong et al. [39]. With respect to the coordination number, we find an increase for first W-O coordination and opposite behaviour of the W-O coordination shell.

From a comparative point a view of the $\mathrm{PW}_{12}$ structure supported on $\mathrm{SiO}_{2}, \mathrm{TiO}_{2}$ and $\mathrm{ZrO}_{2}$ by two preparation routes, we identify that the samples prepared by two methodologies present structural modifications at short order, mainly for $\mathrm{PW}_{12}$ on $\mathrm{TiO}_{2}$ and $\mathrm{ZrO}_{2}$ (shift towards lower bond lengths and considerable changes in the coordination number). However, in the case of samples prepared by the solvothermal method (route exA), major structural variations in $\mathrm{PW}_{12}$ has been observed for all oxide supports analyzed. Besides, larger modifications are localized at longer interatomic distances for the $\mathrm{W}$ structure supported on $\mathrm{TiO}_{2}$ and $\mathrm{ZrO}_{2}$ (see Figure 9(B)). These variations in the local coordination at larger distances may be related to the incorporation of Ti or $\mathrm{Zr}$ atoms into $\mathrm{PW}_{12}$ structure. The large structural modifications found both in the $\mathrm{PW}_{12}$ cluster prepared on $\mathrm{TiO}_{2}$ and $\mathrm{ZrO}_{2}$ may be related to a larger octahedral coordination of $\mathrm{W}$ species observed by XANES, which is higher for the samples prepared solvothermally than those obtained by impregnation of the home prepared oxide.

\subsection{Measurements of number and strength of acidic sites}

The acid properties of bare and HPAs supported samples were evaluated by $\mathrm{NH}_{3}$-TPD experiments carried out from room temperature up to $600^{\circ} \mathrm{C}$. Such high temperature was chosen in order to detect also the contribution of strong acid sites that are known to desorb $\mathrm{NH}_{3}$ at temperatures higher than $550{ }^{\circ} \mathrm{C}$. However, in the range of temperatures selected both Keggin and Wells-Dawson acids still preserve their structure $[9,10]$. $\mathrm{NH}_{3}-\mathrm{TPD}$ technique gives information on the total acidity of the catalysts without distinguishing between Brönsted and Lewis acid sites. The amount of $\mathrm{NH}_{3}$ desorbed ( $\mathrm{ppm} / \mathrm{g}$ HPAs) gives a quantitative evaluation of the number of active sites, while the temperature of desorption is an indication of the strength of the acid sites. $\mathrm{NH}_{3}-\mathrm{TPD}$ profiles displayed by pristine $\mathrm{PW}_{12}, \mathrm{P}_{2} \mathrm{~W}_{18}$, and $\mathrm{SiO}_{2}$ and $\mathrm{TiO}_{2}$ supported HPAs ( $1^{\text {st }}$ set of catalysts, Table 1) were investigated in a previous paper and compared with commercial bare supports, $\mathrm{SiO}_{2}$ and $\mathrm{TiO}_{2}$ [24]. Briefly, for all of the materials no important $\mathrm{NH}_{3}$ desorption occurs at temperature below $200^{\circ} \mathrm{C}$, suggesting the absence of weak acid sites [30]. For bare and $\mathrm{SiO}_{2}$ supported $\mathrm{P}_{2} \mathrm{~W}_{18}$ the main desorption occurs with a broad and intense peak centred at $495^{\circ} \mathrm{C}$ corresponding to ca. 15,000 and to $13,000 \mathrm{ppm}$ of $\mathrm{NH}_{3}$ desorbed per gram of HPA, respectively. A pronounced shoulder at around $300{ }^{\circ} \mathrm{C}$ was also detected for $\mathrm{P}_{2} \mathrm{~W}_{18} / \mathrm{SiO}_{2}$ and it can be concluded that such low temperature feature is due to the contribution of $\mathrm{SiO}_{2}$ Brönsted medium acid 
sites. Unlike $\mathrm{P}_{2} \mathrm{~W}_{18}$ samples, in the case of bare and $\mathrm{SiO}_{2}$ supported $\mathrm{PW}_{12}$ the main desorption peak of ammonia (around 10,000 ppm/g HPA) was detected at $600^{\circ} \mathrm{C}$ indicating that the acid sites in Keggin heteropolyacid are stronger than those of Wells-Dawson HPA. Moreover, the presence of $\mathrm{NH}_{3}$ desorption peaks at 495 and at 600 ${ }^{\circ} \mathrm{C}$, respectively, in the TPD curves of $\mathrm{SiO}_{2}$ supported $\mathrm{P}_{2} \mathrm{~W}_{18}$ and $\mathrm{PW}_{12}$, confirms that the acidic strength typical of the HPAs is maintained after their deposition over silica.

As far as the $\mathrm{NH}_{3}$-TPD curves of $\mathrm{TiO}_{2}$ supported HPAs are concerned ( $1^{\text {st }}$ set of catalysts) [24], a broad peak centred at around $425^{\circ} \mathrm{C}$, typical of medium strength acid sites as those detected for $\mathrm{TiO}_{2}$, was observed for both samples. Moreover, the peaks corresponding to the strong Brönsted acid sites typical of the HPAs were detected at $495^{\circ} \mathrm{C}$ (ca. $12,000 \mathrm{ppm}$ of $\mathrm{NH}_{3} / \mathrm{g} \mathrm{HPA}$ ) for $\mathrm{P}_{2} \mathrm{~W}_{18} / \mathrm{TiO}_{2}$ and at $600^{\circ} \mathrm{C}$ (ca. $6,000 \mathrm{ppm} \mathrm{NH} / \mathrm{g} \mathrm{HPA}$ ) for $\mathrm{PW}_{12} / \mathrm{TiO}_{2}$. Such statement suggests that the samples $\mathrm{P}_{2} \mathrm{~W}_{18}$ and $\mathrm{PW}_{12}$ deposited over commercial $\mathrm{TiO}_{2}$ preserve the strong Brönsted acidity typical of the HPAs.

Acidity characterization of the second and third set of catalysts (present work) was also performed by $\mathrm{NH}_{3}-$ TPD experiments. The profiles displayed by $\mathrm{PW}_{12}$ deposited by impregnation on home-prepared oxides $\left(2^{\text {nd }}\right.$ set, A series) and $\mathrm{PW}_{12} /$ oxides prepared by solvothermal method ( $3^{\text {rd }}$ set, ex A series) are reported in Figure 10.
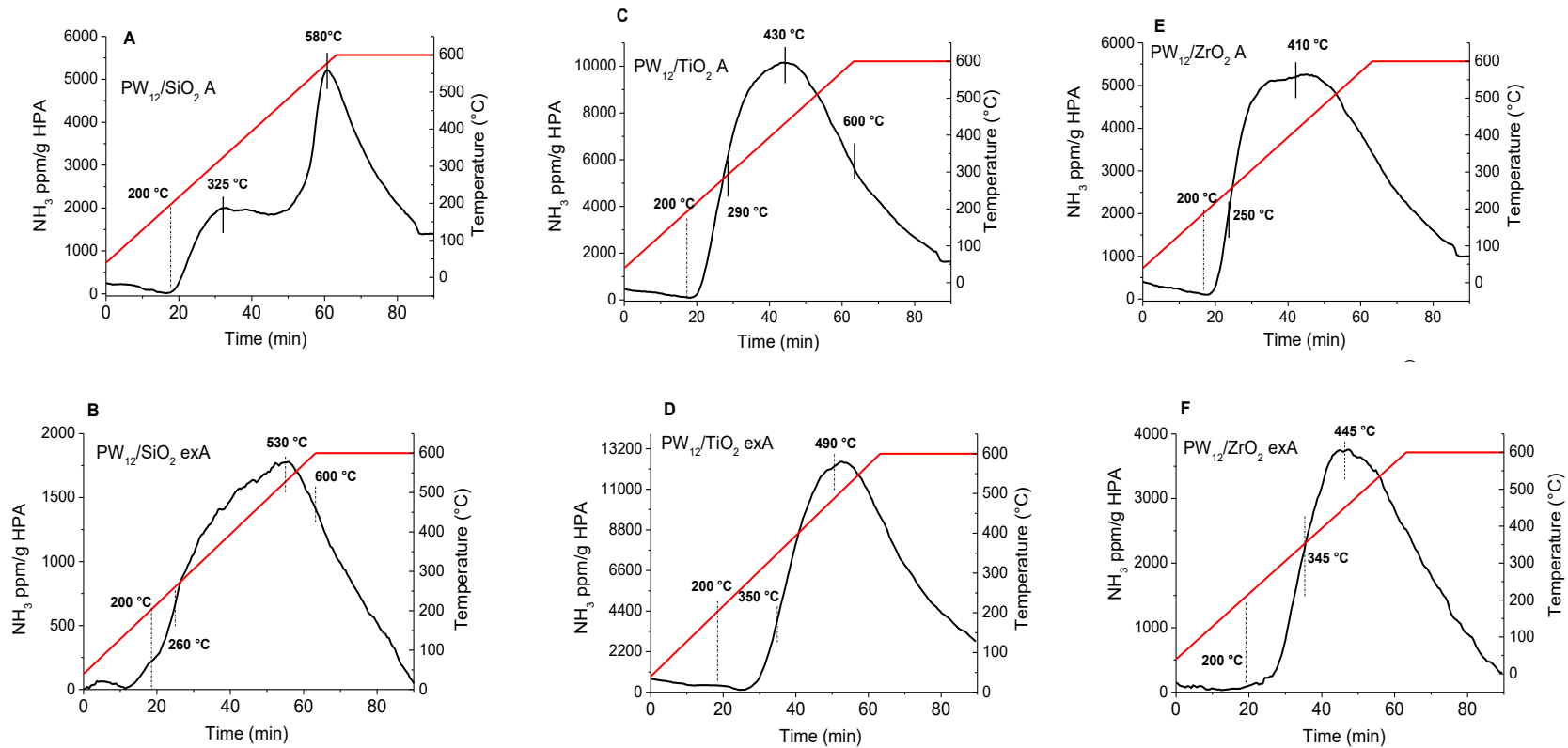

FIGURE 10. $\mathrm{NH}_{3}$-TPD profiles obtained for (A) $\mathrm{PW}_{12} / \mathrm{SiO}_{2} \mathrm{~A}$; (B) $\mathrm{PW}_{12} / \mathrm{SiO}_{2}$ exA; (C) $\mathrm{PW}_{12} / \mathrm{TiO}_{2} \mathrm{~A}$; (D) $\mathrm{PW}_{12} / \mathrm{TiO}_{2}$ exA; (E) $\mathrm{PW}_{12} / \mathrm{ZrO}_{2} \mathrm{~A}$ and (F) $\mathrm{PW}_{12} / \mathrm{ZrO}_{2}$ exA samples.

The $\mathrm{NH}_{3}$-TPD profile recorded for $\mathrm{PW}_{12} / \mathrm{SiO}_{2} \mathrm{~A}$ (Figure 10(A)) shows a similar shape as for the analogous HPA over commercial silica (data so far discussed and ref. 24), however, the number of acid sites was lower for $\mathrm{PW}_{12} / \mathrm{SiO}_{2} \mathrm{~A}$ (a maximum of 5,200 ppm NH $\mathrm{NH}_{3} / \mathrm{g} \mathrm{HPA}$ was desorbed at $580{ }^{\circ} \mathrm{C}$ ) with respect to those showed by $\mathrm{PW}_{12} / \mathrm{SiO}_{2}$. An effect of the nature of silica on the dispersion of the HPA and, therefore, on the acidity can be speculated. A further decrease of the acidic sites number and acidic strength occurs by looking at the desorption curve displayed by $\mathrm{PW}_{12} / \mathrm{SiO}_{2}$ ex A (a maximum of $1,775 \mathrm{ppm} \mathrm{NH} / \mathrm{g} \mathrm{HPA}$ was desorbed at 530 ${ }^{\circ} \mathrm{C}$, Figure 10(B)), suggesting that the solvothermal preparation method may affect additionally the acidic properties of the supported HPA.

The sample $\mathrm{PW}_{12} / \mathrm{TiO}_{2} \mathrm{~A}$, (Figure $10 \mathrm{C}$ ), shows a broad peak centred at around $430{ }^{\circ} \mathrm{C}$ with a maximum value of $10,000 \mathrm{ppm} \mathrm{NH}_{3} / \mathrm{g}$ HPA. In accordance with our previous results [24], such peak was attributed to Lewis acid sites of $\mathrm{TiO}_{2}$ along with the Brönsted acid sites of medium strength generated after supporting the HPA over titania. By increasing the desorption temperature up to $600{ }^{\circ} \mathrm{C}$, the asymmetrical shape of the curve exhibits a weak shoulder without, however, the desorption peak typical of the pristine $\mathrm{PW}_{12}$. This finding, thus, 
confirms that the home-prepared $\mathrm{TiO}_{2}\left(161 \mathrm{~m}^{2} / \mathrm{g}\right)$ inducing a better dispersion of the HPA than the commercial support $\left(52 \mathrm{~m}^{2} / \mathrm{g}\right)$, gives rise to a decrease of the acidic strength of the HPA, with the disappearance of the strong acidic sites typical of the pristine HPA units.

A similar behaviour was detected for the solvothermally prepared catalyst, $\mathrm{PW}_{12} / \mathrm{TiO}_{2}$ exA, Figure 10 (D), that was characterized by somehow higher acidity than the analogous sample A with the presence mainly of medium strength acid sites (up to $12,500 \mathrm{ppm} \mathrm{NH}_{3} / \mathrm{g} \mathrm{HPA}$ desorbed at $490{ }^{\circ} \mathrm{C}$ ), without any evident feature of strong acidity.

As it concerns $\mathrm{NH}_{3}$-TPD profiles of $\mathrm{PW}_{12} / \mathrm{ZrO}_{2} \mathrm{~A}$ and $\mathrm{PW}_{12} / \mathrm{ZrO}_{2}$ exA (Figure $10 \mathrm{E}, \mathrm{F}$ ), both samples were characterized by medium acidic sites desorbing $\mathrm{NH}_{3}$ (a maximum of 5,100 ppm $\mathrm{NH}_{3} / \mathrm{g}$ HPA desorbed in the case of $\mathrm{PW}_{12} / \mathrm{ZrO}_{2}$ A at ca. $410{ }^{\circ} \mathrm{C}$, while $3,765 \mathrm{ppm} \mathrm{NH} / \mathrm{g}$ HPA desorbed at ca. $445^{\circ} \mathrm{C}$ for $\mathrm{PW}_{12} / \mathrm{ZrO}_{2}$ exA). In the overall, the so far reported data support previous findings that the nature of the supports along with the preparation method, especially the solvothermal treatment, affects the dispersion and structure of the HPA units and consequently the type and strength of acidic sites.

\subsection{Relation between characterization of the supported HPAs and catalytic activity}

Catalytic experiments for 2-propanol dehydration forming propene and propene hydration to obtain 2propanaol has been carried out by using pristine and supported Keggin and Wells-Dawson HPAs and they were reported in some previous papers [24,26,29-31]. Table 5 summarises the reaction rates for these two catalytic reactions at $85^{\circ} \mathrm{C}$ in the presence of the pristine HPAs and the supported HPAs characterised in the current research. The heteropolyacid species played always the key role as catalysts in the mechanism of the reaction [29]. As seen in Table 5, the Wells-Dawson HPA presented a higher catalytic 2-propanol dehydration activity than the Keggin one particularly when supported.

In order to correlate the different catalytic activity observed by using the various binary materials, it is fundamental to consider that it is strongly dependent on the Brönsted acidity of the HPA present in the catalyst. Indeed, the activity of bare supports $\left(\mathrm{SiO}_{2}, \mathrm{TiO}_{2}\right.$ and $\left.\mathrm{ZrO}_{2}\right)$ versus 2-propanol dehydration or propene hydration was negligible and consequently it has been concluded that their acid sites are not suitable for dehydration/hydration reactions. Of course, the specific surface area of the supports and the dispersion of the HPA on the oxide along with the interaction between the heteropolyacid and the support could also influence the activity. In particular, as far as the last insight is concerned, the metal-oxygen cluster deformation induced by the HPA-support interaction could modify the acidity of the composites influencing its catalytic activity. The XANES/EXAFS study carried out in this work gave information on this aspect.

TABLE 5. Catalytic 2-propanol dehydration and propene hydration reaction rates by using the various supported HPAs materials. Acidic values in terms of $\mathrm{NH}_{3}$ desorbed [ppm. ${ }^{-1}{ }_{\mathrm{HPA}}$ ] and SSA values are also reported.

\begin{tabular}{|c|c|c|c|}
\hline Sample & $\begin{array}{c}\text { 2-propanol dehydration } \\
\mathrm{r}\left[\mathrm{mmol} \cdot \mathrm{h}^{-1} \cdot \mathrm{g}^{-1} \mathrm{HPA}\right]\end{array}$ & $\begin{array}{c}\text { Propylene hydration } \\
\mathrm{r}\left[\mathrm{mmol} \cdot \mathrm{h}^{-1} \cdot \mathrm{g}^{-1} \mathrm{HPA}\right]\end{array}$ & $\begin{array}{c}\text { Maximum value of desorbed } \mathrm{NH}_{3} \\
{\left[\mathrm{ppm} \cdot \mathrm{g}^{-1} \mathrm{HPA}\right]}\end{array}$ \\
\hline $\mathrm{PW}_{12}$ & $0.35 \pm 0.02$ & $0.18 \pm 0.01$ & $10,000[24]$ \\
\hline $\mathrm{PW}_{12} / \mathrm{SiO}_{2}$ & $3.0 \pm 0.15$ & $1.3 \pm 0.05$ & $10,000[24]$ \\
\hline $\mathrm{PW}_{12} / \mathrm{SiO}_{2} \mathrm{~A}$ & $1.9 \pm 0.10$ & $1.7 \pm 0.10$ & 5,200 \\
\hline $\mathrm{PW}_{12} / \mathrm{SiO}_{2}$ exA & $0.50 \pm 0.02$ & $1.3 \pm 0.10$ & 1,775 \\
\hline $\mathrm{PW}_{12} / \mathrm{TiO}_{2}$ & $4.8 \pm 0.20$ & $1.3 \pm 0.10$ & $6,000[24]$ \\
\hline $\mathrm{PW}_{12} / \mathrm{TiO}_{2} \mathrm{~A}$ & $1.0 \pm 0.05$ & $1.5 \pm 0.10$ & 10,000 \\
\hline $\mathrm{PW}_{12} / \mathrm{TiO}_{2}$ exA & $0.15 \pm 0.01$ & negligible & 12,500 \\
\hline $\mathrm{PW}_{12} / \mathrm{ZrO}_{2} \mathrm{~A}$ & $0.50 \pm 0.02$ & $0.74 \pm 0.03$ & 5,000 \\
\hline $\mathrm{PW}_{12} / \mathrm{ZrO}_{2}$ exA & $0.20 \pm 0.01$ & negligible & 3,765 \\
\hline $\mathrm{P}_{2} \mathrm{~W}_{18}$ & $1.7 \pm 0.10$ & - & $15,260[24]$ \\
\hline
\end{tabular}




\begin{tabular}{|c|c|c|c|}
\hline $\mathrm{P}_{2} \mathrm{~W}_{18} / \mathrm{SiO}_{2}$ & $3.6 \pm 0.15$ & - & $12,780[24]$ \\
\hline $\mathrm{P}_{2} \mathrm{~W}_{18} / \mathrm{TiO}_{2}$ & $6.9 \pm 0.35$ & - & $12,200[24]$ \\
\hline
\end{tabular}

In general, it was observed that the activity of the materials for 2-propanol dehydration to propene was higher for the catalyst in which Keggin and Wells-Dawson structures were impregnated on the commercial $\mathrm{SiO}_{2}$ and $\mathrm{TiO}_{2}$ oxides; in these cases, we observed that not significant modifications in the local structure of the HPAs occurs. On the other hand, the lowest activity values were obtained for those materials in which the HPA clusters showed higher coordination of $\mathrm{W}$ at the first W-O distance, a larger shortening of the second W-O bond length, a lower distortion of the $\mathrm{W}$ octahedron and variations in the shape of the XANES profile. In particular, these characteristics were observed for $\mathrm{PW}_{12} / \mathrm{TiO}_{2}$ exA and $\mathrm{PW}_{12} / \mathrm{ZrO}_{2}$ exA that were the least active samples. In these cases, it was also found that $\mathrm{Ti}$ and $\mathrm{Zr}$ could be incorporated into the $\mathrm{PW}_{12}$ clusters giving to the destruction of a characteristic W arrangement in the cluster. Unfortunately, it was impossible to individuate an unambiguous correlation between the catalyst acidity (in terms of maximum amount of ammonia desorbed) and the interaction HPA-support, however, the shape of TPD profiles reflects the interaction of the HPAs with the supports and the modification occurring as a function of the preparation method, especially for exA samples. The difficulty to correlate the number and the strength of the acid sites present in the catalysts with the catalytic activity is due to the impossibility to discriminate, by $\mathrm{NH}_{3}-\mathrm{TPD}$, between Brönsted and Lewis acidity. Indeed, the catalytic activity seems governed by the presence of medium and strong Brönsted acid sites, consequently some samples like $\mathrm{PW}_{12} / \mathrm{TiO}_{2} \mathrm{~A}, \mathrm{PW}_{12} / \mathrm{TiO}_{2}$ exA and $\mathrm{PW}_{12} / \mathrm{ZrO}_{2}$ exA showing the largest coordination and structural changes by XANES and EXAFS results, although desorbing a large quantity of ammonia, show a low catalytic activity because probably their adsorption sites are essential of Lewis type deriving from the support (it was reported in a previous study that the destruction of HPA Keggin structure occurs during the synthesis due to its reaction with the products of metal alkoxydes hydrolysis [26]). Therefore, the acid-base interaction between HPAs and the support can affect the local structure of W atoms clearly influencing the catalytic response of the binary material. A more deep investigation to discriminate about the amount of Brönsted and Lewis acid sites (for instance by IR spectroscopy upon pyridine adsorption, [40]) will be useful to better understand what type of these sites are most important for the catalytic activity, but this topic will be investigated in a next study.

As far as the propene hydration reaction concerns, it can be observed that, with the only exception of the $\mathrm{PW}_{12} / \mathrm{TiO}_{2}$ exA and $\mathrm{PW}_{12} / \mathrm{ZrO}_{2}$ exA samples, the various catalysts showed very similar activity that was not affected by their different acidity. This apparent contradiction can be easily explained by considering the nonpolar nature of propene that hindering its adsorption on the catalyst surface induce a levelling effect of the catalytic activity. On the other hand, the hypothesized Lewis acidity present on $\mathrm{PW}_{12} / \mathrm{TiO}_{2}$ exA and $\mathrm{PW}_{12} / \mathrm{ZrO}_{2}$ exA samples, and the interaction between the HPAs and the corresponding support that modify the cluster structure as we found by EXAFS analysis, could be also in this case responsible for the very low activity showed by these two catalysts.

\section{Conclusions}

The local structure of heteropolyacids, Keggin $\left(\mathrm{H}_{3} \mathrm{PW}_{12} \mathrm{O}_{40}\right)$ and Wells-Dawson $\left(\mathrm{H}_{6} \mathrm{P}_{2} \mathrm{~W}_{18} \mathrm{O}_{62}\right)$, supported on different materials both commercial and home prepared $\left(\mathrm{SiO}_{2}, \mathrm{TiO}_{2}\right.$ and $\left.\mathrm{ZrO}_{2}\right)$ has been studied by XAS. The results were related with those deriving from surface and bulk characterization techniques (in particular, XPS and acidic amount/strength sites measurements) and with the catalytic activity of the same binary materials both for propene hydration and 2-propanol dehydration in gas-solid regime. The results reveal that the deposition of HPA by impregnation or solvothermal treatment on $\mathrm{SiO}_{2}$ does not produce significant distortions in the $\mathrm{H}_{3} \mathrm{PW}_{12} \mathrm{O}_{40}$ cluster structure due to the poor silica basicity and hence weak interaction. More basic supports such as $\mathrm{TiO}_{2}$ and $\mathrm{ZrO}_{2}$ provide stronger HPA-metal oxide interactions deforming the immobilized HPA and significantly affecting the first coordination shell of $\mathrm{W}$ atoms even by using mild impregnation conditions to support the HPA on the oxide. Noteworthy, the in-situ solvothermal preparation of $\mathrm{TiO}_{2}$ and $\mathrm{ZrO}_{2}$ 
with HPA leads to the destruction of HPA Keggin structure due to its reaction with the products of metal alkoxydes hydrolysis, as a result, the catalytic activity of such materials is poor.

The fitting of $\mathrm{W} \mathrm{L}_{3}$-edge EXAFS spectra of the $\mathrm{HPA} / \mathrm{SiO}_{2}$ and $\mathrm{HPA} / \mathrm{TiO}_{2}$ prepared by impregnation on commercial or home prepared oxides revealed only a slight increment of the coordination number of the tungsten atom both in $\mathrm{W}=\mathrm{O}$ and $\mathrm{W}-\mathrm{O}-\mathrm{W}$ bonds, suggesting that the supported HPAs remained almost intact. The solvothermal preparation of the analogous binary material gave almost the same result for $\mathrm{HPA} / \mathrm{SiO}_{2}$, however, on the contrary, drastically affected the $\mathrm{W}$ arrangement in $\mathrm{HPA} / \mathrm{TiO}_{2}$ and $\mathrm{HPA} / \mathrm{ZrO}_{2}$. The increase of the coordination number of $\mathrm{W}=\mathrm{O}$ and the decrease of that of the $\mathrm{W}-\mathrm{O}-\mathrm{W}$, in addition to variations in the $\mathrm{W}-\mathrm{O}$ distances, implied the occurrence of strong HPA interactions with the $\mathrm{TiO}_{2}$ and $\mathrm{ZrO}_{2}$ surfaces. For the solvothermal preparation of the HPA/oxide binary materials, the increase of the $\mathrm{W}=\mathrm{O}$ coordination number followed the sequence $\mathrm{SiO}_{2}<\mathrm{TiO}_{2}<\mathrm{ZrO}_{2}$ having the values of 1.3, 3.8, 4.4, respectively. These dramatic changes were explained by the partial destruction of the HPA cluster forming $\mathrm{WO}_{3}$ species due to the interaction between the cluster and support. These modifications, in addition to the bulk and surface features of the supported HPAs, influenced the reaction performance of the catalytic 2-propanol dehydration to a significant extent. On the contrary, the propylene hydration was less affected probably due to the propene nonpolar nature that hinders it adsorption on the catalyst surface.

\section{Acknowledgements}

IK acknowledges the financial support from Spanish MINECO (MAT2016-78155-C2-1-R), Gobierno del Principado de Asturias (GRUPIN-ID2018-170) and from Ministry of Education and Science of the Russian Federation (grant No. 4.9722.2017/8.9). LFL is grateful to progetto di Ricerca ARS01_00637 Energie per l'Ambiente-TARANTO (PNR 2015-2020) for financial support. We acknowledge The European Synchrotron (The ESRF), MINECO, and CSIC for the provision of measurements using the BM25-SpLine beamline. We also thank the BM25-SpLine staff for the technical support beyond their duties.

\section{References}

[1] Pope M.T., Müller A., Polyoxometalate Chemistry: An Old Field with New Dimensions in Several Discipline Polyoxometalate Chemistry: An Old Field with New Dimensions in Several Discipline, Angew. Chem Int. Ed. Engl. 1991, 30, 34-48.

[2] Kozhevnikov V., Catalysis by Heteropoly Acids and Multicomponent Polyoxometalates in Liquid-Phase Reactions, Chem. Rev. 1998, 98, 171-198.

[3] Mizuno N., Misono M., Heterogeneous Catalysis, Chem. Rev. 1998, 98, 199-218.

[4] Misono M., Recent Progress in the Practical Applications of Heteropolyacid and Perovskite Catalysts: Catalytic Technology for the Sustainable Society, Catal. Today 2009, 144, 285-291.

[5] Papaconstantinou E., Photochemistry of Polyoxometallates of Molybdenum and Tungsten and/or Vanadium, Chem. Soc. Rev. 1989, 18, 1-33.

[6] Marcì G., García-López E. I., Palmisano L., Heteropolyacid-Based Materials as Heterogeneous Photocatalysts, Eur. J. Inorg. Chem. 2014, 21-35.

[7] Okuhara T., Mizuno N., Misono M., Catalytic Chemistry of Heteropoly Compounds, Adv. Catal. 1996, 41,113-252.

[8] Raj G., Swalus C., Arendt E., Eloy P., Devillers M., Gaigneaux E. M., Controlling the Dispersion of Supported Polyoxometalate Heterogeneous Catalysts: Impact of Hybridization and the Role of Hydrophilicityhydrophobicity Balance and Supramolecularity, J. Nanotechnol. 2014, 5, 1749-1759.

[9] Briand L. E., Baronetti G. T., Thomas H. J., The State of the Art on Wells-Dawson Heteropolycompounds: A Review of their Properties and Applications, Applied Catal. A 2003, 256, 37-50. 
[10] Shikata S., Misono M., Strong Influence of the Polyanion Structure on the Secondary Structure of Solid Heteropolyacids and their Catalytic Activity; Methyl tert-butyl ether Synthesis in the Pseudo-liquid Phase of Heteropolyacids, Chem Commun. 1998, 1293-1294.

[11] Ivanov A.V., Zausa E., Ben Taarit Y., Essayem N., Mechanism of Propene Hydration Over Heteropolyacid Catalysts, Appl. Catal. A 2003, 256, 225-242.

[12] Micek-Ilnicka A., The Role of Water in the Catalysis on Solid Heteropolyacids, J. Mol. Catal. 2009, 308, $1-14$.

[13] Schnee J. and Gaigneaux E.M., Elucidating and Exploiting the Chemistry of Keggin Heteropolyacids in the Methanol-to-DME Conversion: Enabling the Bulk Reaction Thanks to Operando Raman, Cat. Sci. Technol. 2017, 7, 817-830.

[14] Kozhevnikov I.V., Catalysis for Fine Chemical Synthesis. Vol. 2: Catalysis by Polyoxometalates. John Wiley and Sons, Chichester, 2002.

[15] Cavani F., Comuzzi C., Dolcetti G., Etienne E., Finke R., Selleri G., Trifiro F., Trovarelli A., Oxidative Dehydrogenation of Isobutane to Isobutene: Dawson-type Heteropolyoxoanions as Stable and Selective Heterogeneous Catalysts, J. Catal. 1996, 160, 317-321.

[16] Shikata S., Okuhara T., Misono M., Catalysis by Heteropoly Compounds. Gas Phase Synthesis of Methyl Tert-butyl Ether Over Heteropolyacids, J. Mol. Catal. A 1995, 100, 49-59.

[17] Tachikawa T., Fujitsuka M., Majima T., Mechanistic Insight into the $\mathrm{TiO}_{2}$ Photocatalytic Reactions: Design of New Photocatalysts, J. Phys. Chem. C 2007, 111, 5259-5275.

[18] Park H., Choi W., Photoelectrochemical Investigation on Electron Transfer Mediating Behaviors of Polyoxometalate in UV-Illuminated Suspensions of $\mathrm{TiO}_{2}$ and Pt/TiO 2 , J. Phys. Chem. B 2003, 107, 3885-3890. [19] Schnee J., Eggermont A., Gaigneaux E. M., Boron Nitride: A Support for Highly Active Heteropolyacids in the Methanol-to-DME Reaction, ACS Catalysis 2017, 7, 4011-4017.

[20] García-López E.I., Marcì G., Pomilla F.R., Liotta L.F., Megna B., Paganini M.C., Gionco C., Giamello E., Palmisano L., Improved (Photo)catalytic Propene Hydration in a Gas/Solid System by Using Heteropolyacid/Oxide Composites: Electron Paramagnetic Resonance, Acidity, and Role of Water, Eur. J. Inorg. Chem. 2017, 1900-1907.

[21] Yamazoe S., Hitomi Y., Shishido T., Tanaka T., XAFS Study of Tungsten $\mathrm{L}_{1}$ - and $\mathrm{L}_{3}$-Edges: Structural Analysis of $\mathrm{WO}_{3}$ Species Loaded on $\mathrm{TiO}_{2}$ as a Catalyst for Photo-oxidation of $\mathrm{NH}_{3}$, J. Phys. Chem. C 2008, $112,6869-6879$.

[22] Newman A.D., Brown D.R., Siril P., Lee A.F., Wilson K., Structural Studies of High Dispersion $\mathrm{H}_{3} \mathrm{PW}_{12} \mathrm{O}_{40} / \mathrm{SiO}_{2}$ Solid Acid Catalysts, Phys. Chem. Chem. Phys. 2006, 8, 2893-2902.

[23] Carrier X., Marceau E., Carabineiro H., Rodríguez-González V., Che M., EXAFS Spectroscopy as a Tool to Probe Metal-support Interaction and Surface Molecular Structures in Oxide-supported Catalysts: Application to $\mathrm{Al}_{2} \mathrm{O}_{3}$-supported $\mathrm{Ni}(\mathrm{II})$ Complexes and $\mathrm{ZrO}_{2}$-supported Tungstates, Phys. Chem. Chem. Phys. 2009, 11, 7527-7539.

[24] García-López E. I., Marcì G., Pomilla F. R., Liotta L. F., Palmisano L., Enhanced (Photo)catalytic Activity of Wells-Dawson $\left(\mathrm{H}_{6} \mathrm{P}_{2} \mathrm{~W}_{18} \mathrm{O}_{62}\right)$ in Comparison to Keggin $\left(\mathrm{H}_{3} \mathrm{PW}_{12} \mathrm{O}_{40}\right)$ Heteropolyacids for 2-Propanol Dehydration in Gas-Solid Regime, Appl. Catal. A 2016, 528, 113-122.

[25] Sambeth J.E., Romanelli G., Autino J.C., Thomas H.J., Baronetti G.T., A Theoretical-Experimental Study of Wells-Dawson Phospho-tungstic Heteropolyacid: An Explanation of the Pseudoliquid or Surface-type Behaviour, Applied Catal A 2010, 378, 114-118.

[26] García-López E. I., Marcì G., Pomilla F. R., Kirpsza A., Micek-Ilnicka A., Palmisano L., Supported $\mathrm{H}_{3} \mathrm{PW}_{12} \mathrm{O}_{40}$ for 2-Propanol (Photo-assisted) Catalytic Dehydration in Gas-solid Regime: The Role of the Support and of the Pseudo-liquid Phase in the (Photo)activity, Applied Catal B 2016, 189, 252-265.

[27] Newville M., Fundaments of XAFS, Consortium for Advanced Radiation Sources, Universidad de Chicago, Chicago 2004.

[28] http://cars9.uchicago.edu/ifeffit/BruceRavel/Horae. 
[29] Marcì G., García-López E., Palmisano L., Comparison Between Catalytic and Catalytic Photo-assisted Propene Hydration by Using Supported Heteropolyacid, Appl. Catal. A 2012, 421-422, 70-78.

[30] Marcì G., García-López E., Bellardita M., Parisi F., Colbeau-Justin C., Sorgues S., Liotta L. F., Palmisano L., Keggin Heteropolyacid $\mathrm{H}_{3} \mathrm{PW}_{12} \mathrm{O}_{40}$ Supported on Different Oxides for Catalytic and Catalytic Photoassisted Propene Hydration, Phys. Chem. Chem. Phys. 2013, 15, 13329-13342.

[31] Marcì G., García-López E., Vaiano V., Sarno G., Sannino D., Palmisano L., Keggin Heteropolyacids Supported on $\mathrm{TiO}_{2}$ Used in Gas-solid (Photo)catalytic Propene Hydration and in Liquid-solid Photocatalytic Glycerol Dehydration, Catal. Today 2017, 281, 60-70.

[32] Orel B., Lavrenčič Štangar U., Hutchings M.G., Kalcher K., Mixed Phosphotungstic Acid/titanium Oxide Gels and Thin Solid Xerogel Films with Electrochromic-ionic Conductive Properties, J. Non-Cryst. Solids 1994, 175, 251-262.

[33] Haber J., Matachowski L., Mucha D., Stoch J., Sarv P., New Evidence on the Structure of Potassium Salts of 12-Tungstophosphoric Acid, $\mathrm{K}_{\mathrm{x}} \mathrm{H}_{3-\mathrm{x}} \mathrm{PW}_{12} \mathrm{O}_{40}$, Inorg. Chem. 2005, 44, 6695-6703.

[34] Jalil P.A., Faiz M., Tabet N., Hambdan N.M., Hussain Z., A Study of the Stability of Tungstophosphoric Acid, $\mathrm{H}_{3} \mathrm{PW}_{12} \mathrm{O}_{40}$, Using Synchrotron XPS, XANES, Hexane Cracking, XRD, and IR Spectroscopy, J. Catal. 2003, 217, 292-299.

[35] Balerna A., Bernieri E., Burattini E., Kuzmin A., Lusis A., Purans J., Cikmach P., XANES Studies of $\mathrm{MeO}_{3-\mathrm{x}}(\mathrm{Me}=\mathrm{W}, \mathrm{Re}, \mathrm{Ir})$ Crystalline and Amorphous Oxides, Nuclear Instrum. Meth. Phys. Res. A 1991, 308, 240-242.

[36] Limaye M.V., Chen J.S., Singh S.B., Shao Y.C., Wang Y.F., Pao C.W., Tsai H.M., Lee J.F., Lin H.J., Chiou J.W., et al, Correlation Between Electrochromism and Electronic Structures of Tungsten Oxide Films, RSC Advances, 2014, 4, 5036-5045.

[37] Tougerti A., Cristol S., Berrier E., Briois V., La Fontaine C., Villain F., Joly Y., XANES Study of Rhenium Oxide Compounds at the $\mathrm{L}_{1}$ and $\mathrm{L}_{3}$ Absorption Edges, Phys. Rev. B 2012, 85, 125136.

[38] Hilbrig F., Göbel H.E., Knözinger H., Schmelz H., Lengeler, B., X-ray Absorption Spectroscopy Study of the Titania- and Alumina-supported Tungsten Oxide System, J. Phys. Chem. 1991, 95, 6973-6978.

[39] Wong S.-T., Li T., Cheng S., Lee J.-F., Mou C.-Y., Aluminum-promoted Tungstated Zirconia Catalyst in n-Butane Isomerization Reaction, J. Catal. 2003, 215, 45-56.

[40] Schnee J., Devred F., Gaigneaux E.M., Vimont A., Assessing the Dispersion of Supported $\mathrm{H}_{3} \mathrm{PW}_{12} \mathrm{O}_{40}$ Catalysts: No Longer a Hurdle Thanks to in Situ IR Upon Pyridine Adsorption, Appl. Catal. A 2019, 578, 116121.

TOC Graphic

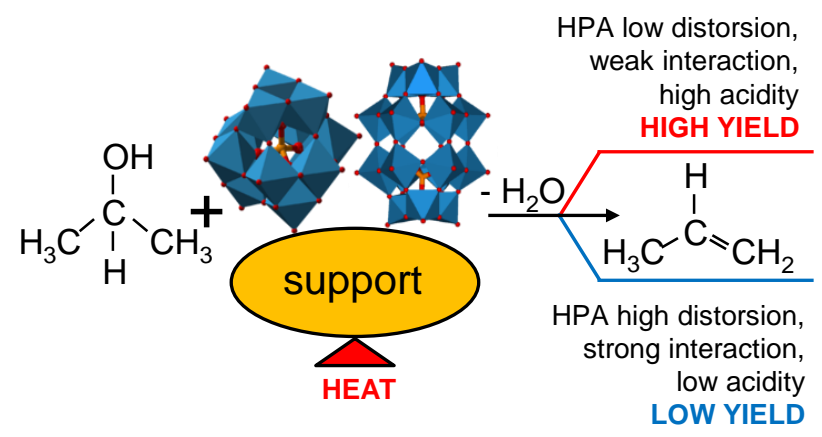

